\title{
Laboratory-generated primary marine aerosol via bubble-bursting and atomization
}

\author{
E. Fuentes ${ }^{1}$, H. Coe ${ }^{1}$, D. Green ${ }^{2}$, G. de Leeuw ${ }^{3,4,5}$, and G. McFiggans ${ }^{1}$ \\ ${ }^{1}$ Centre for Atmospheric Sciences, School of Earth, Atmospheric and Environmental Sciences, Manchester, M13 9PL, UK \\ ${ }^{2}$ Scottish Association for Marine Science, Oban, UK \\ ${ }^{3}$ Finnish Meteorological Institute, Climate Change Unit, Helsinki, Finland \\ ${ }^{4}$ University of Helsinki, Department of Physics, Helsinki, Finland \\ ${ }^{5} \mathrm{TNO}$, Environment, Health and Safety, Utrecht, The Netherlands
}

Received: 7 September 2009 - Published in Atmos. Meas. Tech. Discuss.: 29 September 2009

Revised: 15 January 2010 - Accepted: 18 January 2010 - Published: 5 February 2010

\begin{abstract}
A range of bubble and sea spray aerosol generators has been tested in the laboratory and compared with oceanic measurements from the literature. We have shown that the method of generation has a significant influence on the properties of the aerosol particles produced. Hence, the validity of a generation system to mimic atmospheric aerosol is dependent on its capacity for generating bubbles and particles in a realistic manner. A bubble-bursting aerosol generator which produces bubbles by water impingement was shown to best reproduce the oceanic bubble spectral shapes, which confirms previous findings.

Two porous bubblers and a plunging-water jet system were tested as bubble-bursting aerosol generators for comparison with a standard nebulizer. The methods for aerosol production were evaluated by analysing the bubble spectrum generated by the bubble-bursting systems and the submicron size distribution, hygroscopicity and cloud condensation nucleus activity of the aerosols generated by the different techniques. Significant differences in the bubble spectrum and aerosol properties were observed when using different aerosol generators.

The aerosols generated by the different methods exhibited similar hygroscopicity and cloud condensation nucleus activity behaviour when a sample of purely inorganic salts was used as a parent seawater solution; however, significant differences in the aerosol properties were found when using samples of filtered natural seawater enriched with biogenic organics. The presence of organics in the aerosol caused suppression of the growth factor at humidities above $75 \% \mathrm{RH}$ and an increase in the critical supersaturation with respect
\end{abstract}

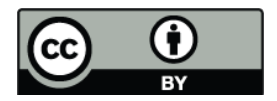

Correspondence to: G. McFiggans (g.mcfiggans@manchester.ac.uk) to the generation from artificial seawater devoid of organics. The extent of the effect of organics on the aerosol properties varied depending on the method of particle production. The results of this work indicate that the aerosol generation mechanism affects the particles organic enrichment, thus the behaviour of the produced aerosols strongly depends on the laboratory aerosol generator employed.

Comparison between bubble lifetimes in several laboratory simulations and the oceanic conditions indicated that it would require a considerable extension of the dimensions of the currently used bubble-bursting laboratory systems in order to replicate the characteristic oceanic bubble lifetimes. We analyzed the implications derived from the reduced bubble residence times in scaled systems, regarding marine surfactants adsorption on rising bubbles, and found that adsorption equilibrium is reached on a timescale much shorter than the bubble lifetime in small-scale laboratory generators. This implies that adsorption of marine surface-active material is not limited by surfactant transport to the bubble surface.

\section{Introduction}

Marine aerosol accounts for the majority of the global natural aerosol flux and consequently, has an important impact on the Earth's radiative budget and biogeochemical cycling (O'Dowd et al., 2004, 2007). Aerosol particles affect the radiative balance of the atmosphere by absorbing and scattering in-coming solar radiation (direct effect) and by affecting the microphysical properties of clouds (indirect effect). The indirect effect is a significant source of uncertainty due to the complexity of the atmospheric interactions involved, as well as the wide range of scales on which these interactions occur (Ramaswamy et al., 2001).

Published by Copernicus Publications on behalf of the European Geosciences Union. 
Sea spray primary particles are produced as a result of breaking wave processes occurring on oceans surfaces. Wind generated waves breaking at wind speeds higher than $4 \mathrm{~ms}^{-1}$ produce sea-spray droplets with sizes from $\leq 1 \mu \mathrm{m}$ to $\geq 25 \mu \mathrm{m}$ (Lewis and Schwartz, 2004). Breaking waves dissipate up to $40 \%$ of their energy and up to $50 \%$ of the energy loss is expended in entraining air in the water bulk and creating a dense plume of bubbles (Rapp and Melville, 1990). The formed bubbles rise and burst upon reaching the surface, thereby producing the so-called film and jet drops. Depending on its size, a bubble can produce up to ten jet drops and several hundreds of film drops. The sea spray total number concentration is normally dominated by particles in the submicron size range from 5 to $300 \mathrm{~nm}$, with a decline in the particle number with increasing size (Fitzgerald, 1991).

The primary marine aerosol is composed of seawater enriched in inorganic and organic chemical compounds as well as with bacteria and viruses (Boehme et al., 1993). Both natural (biogenic) and anthropogenic compounds, dissolved in the near-surface layer of the ocean or as a thin film on the ocean surface, may contribute to the content of marine aerosols. Under breaking wave conditions, the primary mechanism of transport of biogenic surfactants to the ocean surface is by bubble scavenging. When the bubbles reach the water surface, the organics concentrated on their surface are ejected into the atmosphere along with dissolved inorganic constituents of seawater. Thereby, the seawater composition, bubble spectrum, bubble hydrodynamics and the formation and chemical composition of the aerosol are closely interrelated and interdependent (Duce and Hoffman, 1976; Tseng et al., 1992). Chemical analysis of sea spray particles collected in field experiments has provided evidence for the presence of significant concentrations of biogenic organic matter in the submicron size range (Hoffman and Duce, 1977; Novakov et al., 1997; Middlebrook et al., 1998; Putaud et al., 2000; Cavalli et al., 2004). Primary emission of biogenic organic matter originates from the metabolic activity of oceanic phytoplankton and consists of a complex mixture of dissolved and particulate species, including a variety of organic compounds such as carboxylic acids, lipids, amino acids and carbohydrates (Aluwihare and Repeta, 1999). The presence of this organic material in seawater might influence the aerosol production mechanism, by affecting the bubble hydrodynamics, and also the behaviour of the aerosol generated. Secondary organic aerosol formed from biogenic gaseous emissions (Meskhidze and Nenes, 2006), along with anthropogenic and terrestrial natural sources (Stephanou, 1991), also contribute to the organic fraction found in marine aerosols. However, little is known on the effect of the organic matter on the behaviour of atmospheric particles (McFiggans et al., 2006).

A number of laboratory investigations have been conducted in order to study a range of physical and chemical characteristics of marine aerosols, such as size distribution, reactivity, hygroscopicity and cloud activation properties (Mårtensson et al., 2003; Stewart and Cox, 2004; Sven- ningsson et al., 2006; Saul et al., 2006; Niedermeier et al., 2008; Braban et al., 2007). It is a common practice to use atomizers for the generation of laboratory marine aerosol proxies from seawater samples (Svenningsson et al., 2006; Riziq et al., 2006; Saul et al., 2006; McNeill et al., 2006; Braban et al., 2007; Niedermeier et al., 2008; Taketani et al., 2009), while only in a few works the aerosol has been produced by bubble-bursting via aeration through glass frits or diffusers (Cloke et al., 1991; Mårtensson et al., 2003; Keene et al., 2007; Tyree et al., 2007; Wise et al., 2009; Hultin et al., 2009) or using water jets (Cipriano and Blanchard, 1981; Sellegri et al., 2006; Facchini et al., 2008).

Bubble bursting has been simulated in laboratory works to study the marine aerosol size distribution properties. Mårtensson et al. (2003) and Tyree et al. (2007) simulated the production of marine particles by bubbling seawater samples through different porous media. Sellegri et al. (2006) compared the bubble spectrum and the submicron aerosol size distributions generated by using a water recirculation system and aeration through glass frits of different porosity. Some of these investigations also studied the effect of salinity, water temperature (Mårtensson et al., 2003; Tyree et al., 2007; Sellegri et al., 2006) and organic matter by using organic proxies, such as oleic acid (Tyree et al., 2007) and sodium dodecyl sulphate (SDS) (Sellegri et al., 2006).

Although most marine aerosol size distribution studies have given emphasis to the reproduction of particle formation via bubble bursting, the majority of investigations on the aerosol behaviour, such as halogen reactivity (Braban et al., 2007), $\mathrm{N}_{2} \mathrm{O}_{5}$ uptake (Stewart and Cox, 2004; McNeill et al., 2006; Saul et al., 2006), hygroscopic growth (Svenningsson et al., 2006; Niedermeier et al., 2008) and cloud condensation nucleus activity (Svenningsson et al., 2006; Moore et al., 2008) use atomizers as aerosol generators. The real process for marine aerosol formation greatly differs from the aerosol generation induced by the atomization mechanism; however, the extent to which the discrepancy between this technique and the real production processes can affect the aerosol behaviour has not been analysed. The reliability of laboratory aerosol studies depends on the degree to which the aerosol laboratory proxies are able to mimic the behaviour of real aerosols. The properties of such aerosol proxies might be dependent on the generation mechanisms used in the laboratory; however, none of the previously conducted investigations specifically addresses the performance of different laboratory methods as generators of marine aerosol.

Although inorganic sea salt comprises a significant fraction of the sea spray aerosol dry mass composition, organic matter can also contribute to the overall mass (O'Dowd et al., 2007). During high biological activity periods organic matter has been shown to be the dominant component of the non-water mass fraction in the submicron ambient marine aerosol, comprising up to approximately $63 \%$ of the total dry mass (O'Dowd et al., 2004). The role of such organic matter on the behaviour of the marine aerosol remains largely 
Table 1. Summary of experimental conditions for the bubble spectrum and aerosol characterization measurements conducted with spargers as bubble generators. $Q_{\text {air }}=$ total air flow through the porous media, $z=$ depth below water. Sweep air flow in the tank head space was $\sim 3 \mathrm{lpm}$.

\begin{tabular}{lccccc}
\hline & \multicolumn{3}{c}{$\begin{array}{c}\text { Bubble spectra meas. } \\
Q_{\text {air }}(\mathrm{lpm})\end{array}$} & $\begin{array}{c}\text { Aerosol meas. } \\
Q_{\text {air }}(\mathrm{lpm})\end{array}$ & $z(\mathrm{~cm})$ \\
\hline Glass frit & 5.2 & 8.4 & 10 & 5 & 5 \\
Diffuser & 7.6 & 8.1 & 8.5 & 8 & 11 \\
\hline
\end{tabular}

uncertain; hence, further laboratory investigations on sea spray aerosol containing biogenically derived organic matter are needed to clarify the effect of this material on the aerosol properties.

It is likely that both the amount and size fractionation of the organic matter incorporated into the marine aerosol are affected by the mechanism employed for aerosol generation. The use of different aerosol generators may lead to the production of aerosols with varying chemical composition and thus, to a diverging interpretation of the experimental results. Therefore, it is important to determine the impact of the generation techniques on the laboratory synthesized aerosols.

This work presents an experimental study based on the characterization of sea spray particles generated from artificial and natural seawater enriched with biogenic organic matter by using different laboratory techniques. Air injection through porous bubblers and a plunging-water jet system were tested as bubble-bursting aerosol generators and compared with a standard nebulizer. The ability of the bubblebursting techniques to reproduce the real oceanic bubble spectrum signature was analysed by means of a series of optical bubble spectrum measurements. Measurements of size distribution, water uptake and cloud condensation nucleus activity (CCN) of the aerosol produced from organics-free artificial seawater and natural seawater containing biogenic organics were conducted in order to elucidate the extent to which the different techniques employed for aerosol production influence the behaviour of the generated aerosols.

\section{Experimental}

\subsection{Aerosol generation}

Bubble-bursting experiments were performed using a PTFE tank (internal dimensions: $20.5 \mathrm{~cm}$ height, $19.5 \mathrm{~cm}$ width and $27.5 \mathrm{~cm}$ length) of $11 \mathrm{~L}$ capacity. The tank was filled with $6 \mathrm{~L}$ of sample, which resulted in a water depth of $11 \mathrm{~cm}$. Bubble-bursting aerosol formation was simulated by generating bubbles in the bulk of seawater samples using different techniques (Fig. 1). Two systems were employed for the production of bubbles in the tank via injection of
Table 2. Summary of experimental conditions for the bubble spectrum ( 1 water jet) and aerosol characterization measurements ( 8 water jets) in the small-scale plunging water jet system in this study. $Q_{w}=$ total water flow, $v_{1}=$ mean jet velocity at the water surface, $\mathrm{d}_{0}=$ nozzle diameter, $\mathrm{d}_{1}=$ water jet diameter at the water surface, which is assumed $\sim \mathrm{d}_{0}, h=$ vertical distance from the nozzle to the water surface, $z=$ penetration depth. Inflow conditions are defined by $h / d_{1}$ and $F r=$ Froude number $=v_{1} /\left(\mathrm{g} \mathrm{d}_{1}\right)^{0.5}$ with g=gravity acceleration $\left(9.81 \mathrm{~m} \mathrm{~s}^{-2}\right)$. Sweep air flow in the tank head space was $\sim 3 \mathrm{lpm}$.

\begin{tabular}{lcccc}
\hline & $\begin{array}{c}\text { Bubble spectra meas. } \\
\text { (1 water jet) }\end{array}$ & $\begin{array}{c}\text { Aerosol meas. } \\
\text { (8 water jets) }\end{array}$ \\
\hline$Q_{w}(\mathrm{lpm})$ & 1 & 1.8 & 5 & 4 \\
$v_{1}\left(\mathrm{~m} \mathrm{~s}^{-1}\right)$ & 1.42 & 1.45 & 1.76 & 1.11 \\
$\mathrm{~d}_{0}(\mathrm{~cm})$ & 1 & 1 & 1 & 0.4 \\
$h(\mathrm{~cm})$ & 10 & 10 & 10 & 4 \\
$z(\mathrm{~cm})$ & 9 & 9 & 10 & 7 \\
$h / \mathrm{d}_{1}$ & 10 & 10 & 10 & 10 \\
$F r$ & 4.52 & 4.64 & 5.61 & 5.59 \\
\hline
\end{tabular}

clean filtered air through porous media: a sintered glass filter (Fisher Sci., $30 \mu \mathrm{m}$ mean pore size) and an aquarium diffuser (Elite Aquarium air stone, unknown pore size). The glass sintered filter and the aquarium diffuser were placed at $5 \mathrm{~cm}$ and $11 \mathrm{~cm}$ below the water surface, respectively. Experimental conditions for the measurements with the glass frit and the diffuser are summarized in Table 1.

A method consisting of the recirculation of water by means of a peristaltic pump was additionally used as bubblebursting aerosol generator. With this technique, air entrained in the water bulk, as a result of water impingement, is dispersed in a plume of bubbles that burst upon reaching the water surface. A single water jet was produced to characterize the bubble spectrum generated by water impingement. In order to generate a statistically significant number of particles for the aerosol experiments, the water flow was divided in eight water jets by using a flow distributor. To ensure a similar dynamical behaviour between the multiple water jet and the single water jet systems, dimensional scaling based on hydrodynamic Froude similitude was applied (Chanson et al., 2004). Similarity of the ratio of inertial to gravitational forces (Froude number=Fr) and inflow conditions (ratio of height over water to nozzle diameter) between hydrodynamic systems implies equal void fractions and normalised bubble spectrum (Chanson et al., 2004). The total water flow and the distance from the nozzles to the water surface were adjusted as to have similar inflow conditions and Froude number in the single and multiple water jet systems. Table 2, which summarizes the experimental conditions for the measurements conducted with the single and multiple water jets, shows the hydrodynamic similarity between these two systems. 


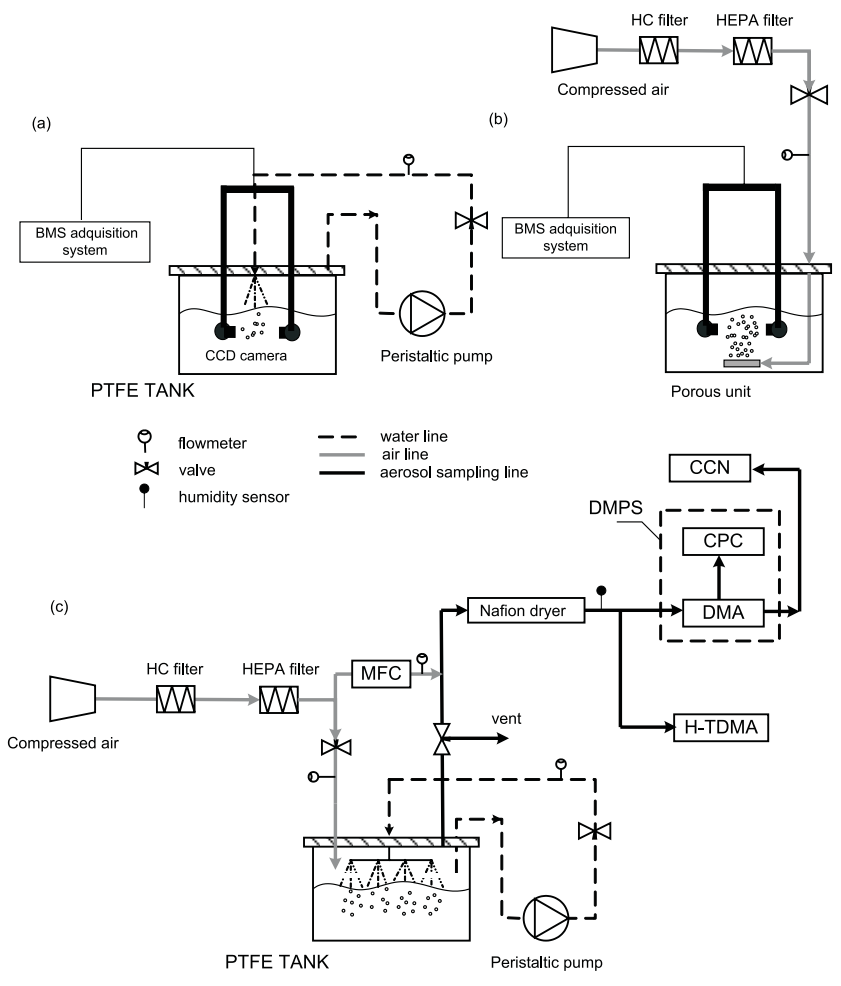

Fig. 1. Schematic of bubble spectrum experiments for (a) the plunging-water jet system and (b) porous media bubblers. (c) Experimental set-up for aerosol size distribution, hygroscopicity and $\mathrm{CCN}$ experiments (the schematic represented corresponds to the plunging-water jet system). BMS=bubble spectrometer, DMPS=differential mobility particle sizer, DMA=differential mobility analyzer, $\mathrm{CCN}=$ cloud condensation nuclei counter, $\mathrm{CPC}=$ particle counter, $\mathrm{H}$-TDMA=Hygroscopic-tandem differential mobility analyzer, $\mathrm{MFC}=$ mass flow controller.

A chemically resistant PTFE composite tube (Masterflex I/P 70) was employed for water recirculation in order to avoid contamination of the water samples and adhesion of surfactants on the tubing wall. The water flow was controlled by setting the peristaltic pump rotating speed in a range of 20 $40 \mathrm{rpm}$ and monitored using a rotameter. The bubble plume penetration distance ranged from 7 to $10 \mathrm{~cm}$, depending on the water recirculation flow and the water jet system employed (Table 2).

For the aerosol experiments the PTFE tank was sealed and swept with a continuous air flow of $3 \mathrm{lpm}$. The humidity of the flow directed from the tank to the aerosol characterization instruments was reduced down to $32-42 \%$ RH by mixing the sample with a 5\% volumetric dry air flow, monitored by a mass flow controller, and by using a Nafion gas dryer. The relative humidity of the sample was monitored with a Rotronics HygroClip SC05 sensor positioned downstream of the Nafion dryer. The humidity was further reduced to $\mathrm{RH}<10 \%$ for the hygroscopicity measurements by means of a gas dryer.
Thorough cleaning procedures were applied in order to minimize the presence of contaminants in the system. An isopropanol and deionised water solution was first recirculated in the PTFE tank and air forced through the porous units for an hour, followed by two sequential tank washes with $5 \mathrm{~L}$ of deionised water. Next, the tank walls and bubbling apparatus were rubbed with chloroform, rinsed and washed with deionised water. In order to rinse the pump tubing and the porous bubblers, deionised water was recirculated through the tank tubing and air was forced through the porous units immersed in water. Finally, the tank was washed twice with $5 \mathrm{~L}$ of deionised water.

The bubble paths and lifetimes in the small-scale systems employed in this study (porous plates and water jets system) are shorter than those expected in real conditions. Smallscale physical models, although not providing the real bubble path lengths, are valid and useful systems to study the dynamic behaviour of bubble plumes. Laboratory systems with a varied range of plume depths, including lengths $<10$ $15 \mathrm{~cm}$ are generally used to study the formation and hydrodynamic evolution of bubble plumes in order to understand the process occurring in oceanic conditions (Cipriano and Blanchard, 1981; Hwang et al., 1990; Leifer et al., 2007). An analysis of this aspect and associated implications, regarding marine surfactants scavenging by rising bubbles, are described in Sects. 4 and 5 of this paper.

For the nebulisation experiments a TOPAS atomizer aerosol generator (ATM 226) was used. In the atomization method a flow of compressed air is introduced in the liquid vessel through the atomizer nozzle, producing a high velocity jet at expansion. As a result of the Bernoulli effect, the aqueous solution is drawn from the atomizer vessel and subsequently, a high-velocity air flow breaks up the solution into droplets, forming the aerosol. Atomization of deionised water and rinsing with isopropanol, chloroform and deionised water were applied for cleaning the atomizer vessel and tubing prior the nebulisation experiments.

\subsection{Materials and methods}

Artificial seawater was prepared from analytical grade salts and deionised water following the method described by Kester (1967) so that the ionic mass ratios of $\mathrm{Na}^{+}, \mathrm{Cl}^{-}$, $\mathrm{Mg}^{2+}, \mathrm{HCO}_{3}^{-}$and $\mathrm{SO}_{4}^{2-}$ were comparable to those in seawater. The salt mixture contained, by mass, $73.6 \% \mathrm{NaCl}, 14.5 \%$ $\mathrm{MgCl}_{2}, 11.5 \% \mathrm{Na}_{2} \mathrm{SO}_{4}$ and $0.004 \% \mathrm{NaHCO}_{3}$. Seawater samples of $35 \%$ salinity were prepared by adjusting the solution density to $1025 \mathrm{~kg} \mathrm{~m}^{-3}$ at $18-20^{\circ} \mathrm{C}$ using a hydrometer.

Natural seawater samples collected from North Atlantic waters were enriched with biogenically-synthesized organic matter by culturing Thalassiosira rotula diatom cells in the laboratory. These samples were used to analyse the aerosol hygroscopicity and CCN activity. Seawater samples were collected near the Scotland coast (UK) from the Tiree passage $\left(56^{\circ} 37.7^{\prime} \mathrm{N}, 6^{\circ} 23.8^{\prime} \mathrm{W}\right)$ by pumping surface water from 
about $5 \mathrm{~m}$ depth into $20 \mathrm{~L}$ carbouys. The seawater collected was aged by exposing the plastic carbouys to the sunlight for about 2-3 months. During the ageing period, algae present in the seawater grew consuming all the nutrients, and the bacteria present in the water used up the organic matter released by the algae. The aged natural seawater was filtered $(\mathrm{GF} / \mathrm{F}$; Whatman) to remove algal and bacteria biomass. The sample was subsequently amended with F/2 nutrients and either selenite or silicate (Guillard, 1975), and sterilised by autoclaving $\left(121^{\circ} \mathrm{C}\right.$ for $\left.15 \mathrm{~min}\right)$ in order to prepare the media for the algal culture. The algal cultures were grown in glass Erlenmeyer flasks fitted with gas permeable stoppers or $20 \mathrm{~L}$ polycarbonate carboys (Nalgene) at $15^{\circ} \mathrm{C}$ with a photon flux density of ca. $70 \mu \mathrm{mol} \mathrm{PAR} \mathrm{m}^{-2} \mathrm{~s}^{-1}$ supplied by cool-white fluorescent lighting (Phillips, Netherlands) with a photoperiod of 12:12 h (light:dark). Monitoring of algal growth was done by measuring in vivo chlorophyll-a fluorescence every 2 days using a Turner Trilogy fluorometer. Harvesting of the organic matter commenced at the point when the cultures in vivo chlorophyll-a measurement peaked. Following algal growth in Erlenmeyer flasks, the cell biomass was removed by filtration through pre-combusted $\left(450^{\circ} \mathrm{C}\right.$ for $\left.8 \mathrm{~h}\right)$ glass fiber filters (GF/F; Whatman) and subsequently through deionisedwater rinsed and sterile polycarbonate filters $(0.2 \mu \mathrm{m}$; Millipore). Large volume algal cultures (10-20 L) were subjected to cross-flow filtration $(0.2 \mu \mathrm{m}$; Schleicher and Schuell) to remove algal and bacterial biomass. The algal organic material was then stored at $-20^{\circ} \mathrm{C}$ and kept frozen until use.

For analysis of the organic content, the seawater samples were aspirated from the filtrate using acid-washed glass pipettes to pre-combusted glass ampules or autosampler bottles and acidified with orthophosphoric acid and stored in the dark at $4{ }^{\circ} \mathrm{C}$ until analysis. Dissolved organic carbon concentration (DOC) analyses was conducted as per standard procedures on a Shimadzu TOC-V CPH/CPN. The concentration of the seawater samples enriched with organics was $512 \mu \mathrm{M}$ DOC, which is on the order of concentration expected in seawater in areas of high biological activity (Ittekot, 1982; Lomas et al., 2001).

\subsection{Bubble spectrum measurements}

The size distribution of bubbles generated in the tank was measured with an optical bubble spectrometer (TNOminiBMS) in the diameter size range from 30 to $1140 \mu \mathrm{m}$. The system consists of a CCD camera which records images of the bubbles generated in the water bulk in a sample volume of $110 \mathrm{~mm}^{3}$ illuminated by a light source. The CCD camera was equipped with a daylight blocking filter and a telescope consisting of two lenses, with focal lengths 40 and $80 \mathrm{~mm}$ (Leifer et al., 2003).

Images acquired by the CCD camera were analysed by image processing software to obtain the bubble size histograms. Bubble size was determined by discriminating the bubble image from the background by image thresholding assuming a spherical bubble shape, while the sample volume and bubble size calibration allowed the calculation of the bubble size distribution.

The measurements were made on the rising column of bubbles at circa $3-8.5 \mathrm{~cm}$ below the water surface and each bubble spectrum was averaged on the images recorded over 2 min. Artificial seawater solutions were used to perform these experiments with the different bubbling systems. The experimental set-up for the bubble spectrum measurements is illustrated in Fig. 1a and b for the plunging-water jet system and the porous bubblers, respectively. All experiments were conducted at room temperature in the range $18-20^{\circ} \mathrm{C}$.

\subsection{Aerosol characterization}

The size distribution of the generated aerosols was measured using a Differential Mobility Particle Sizer (DMPS). The DMPS consists of two Vienna design Differential Mobility Analysers (DMAs) (Williams, 1999; Williams et al., 2007): an ultrafine DMA for particles in the size range $3.4-34 \mathrm{~nm}$ and a standard DMA for particle sizes from $30-830 \mathrm{~nm}$. After transmission through the DMAs, particles are counted using condensation particle counters (CPC). The ultrafine DMA was attached to a TSI 3025A CPC counter and the standard DMA to a TSI 3010 CPC particle counter. The DMAs were operated in parallel and utilised a custom built sealed, recirculating sheath air system, which was humidity controlled and filtered. Particle size distributions in the diameter size range from $3 \mathrm{~nm}$ to $450-830 \mathrm{~nm}$ were obtained as the average of 6 scans during a $60 \mathrm{~min}$ measurement period.

A dual-column continuous flow CCN counter (Droplet Measurement Technologies) combined with a Vienna designed DMA and a particle counter TSI 3010 CPC were employed to characterize the aerosol cloud condensation activity. The DMA was used to generate monodisperse aerosol in the size range between $40 \mathrm{~nm}$ and $110 \mathrm{~nm}$ dry diameter. These particles were directed in parallel to the CPC and CCN counters. The CCN counter sample flow was $0.5 \mathrm{lpm}$ and it was operated at different supersaturations for each particle size in the range between $0.03 \%$ and $1 \%$. The activated fraction was determined from the ratio between the CPC and $\mathrm{CCN}$ counts and the critical supersaturation was estimated as the supersaturation at which $50 \%$ of the particles were activated.

Deliquescence curves of $100 \mathrm{~nm}$ dry diameter particles were measured by means of a Hygroscopicity Tandem Differential Mobility Analyzer (H-TDMA) in order to analyse the aerosol hygroscopicity. The H-TDMA instrument used in this work consists of a bipolar neutraliser, a diffusion dryer, a fixed voltage long column DMA that is used to select a narrow size range of ambient aerosol, a humidification system, a second DMA used to determine the growth of the particles selected by the first DMA and a TSI 3760 CPC counter (Cubison et al., 2005; Gysel et al., 2009). A humidity below 
$10 \% \mathrm{RH}$ was used for particle size selection in the first DMA. The DMAs used were of the Vienna design with a central column length of $0.28 \mathrm{~m}$ and a sheath flow rate of $6 \mathrm{lpm}$.

The experimental set-up for the aerosol characterization is depicted in Fig. 1c, utilising the plunging-water jet as aerosol generation system. The sampling system for the other bubble-bursting methods was identical. Blank measurements were conducted before the experiments by measuring the particle counts in the sample air flow from the tank head space in the absence of bubbles. Bubbling experiments were initiated when the particle counts detected in the blank air were zero. The measurements were corrected for particle losses by considering the calculated transmission efficiency from the tank to the instruments as a function of the particle size. Most particle losses (up to $75 \%$ loss) occurred in the size range below $20 \mathrm{~nm}$, as a result of diffusion.

Due to the limited amount of organics-enriched seawater available, the sample was not replaced during the duration of the aerosol experiments. Time series of particle size distribution measurements did not reveal any significant changes during the duration of the experiments $(1 \mathrm{~h})$. The longest experimental times were those needed to obtain humidograms (about $5 \mathrm{~h}$ ). In order to test if the changes in the concentration due to bubbling could modify the aerosol properties, some of the measurements were replicated, but no significant changes were found in the properties of the aerosol generated.

\subsubsection{Particles morphology considerations}

The shape and morphology of aerosol particles are relevant characteristics which might affect the aerosol sizing methods, through their effects on particle drag and transport properties. Particle size selection in DMA columns is based on the mobility diameter $\left(\mathrm{d}_{m}\right)$, which is dependent on the particle shape. For spherical particles mobility diameter is equivalent to volume diameter $\left(\mathrm{d}_{\mathrm{ve}}\right)$; however, for nonspherical particles this is not the case.

The shape of the particles depends on their chemical composition and generation mechanism. Different types of compounds may form particles of diverse morphology and aerosol particles containing the same compounds could exhibit different structure and shape, depending on differences in particle generation (Rissman et al., 2007). The shape of the formed particles might also depend on the temperature range, the drying process and the addition of surfactants (Iskandar et al., 2003).

For cubic particles, such as $\mathrm{NaCl}$, a standard shape factor of $\chi=1.08$ is generally applied in order to reconcile the mobility and volume equivalent diameters. This correction is necessary to estimate the particles hygroscopic growth and the volume equivalent diameter, usually employed as input parameter for calculations based on the Köhler theory. Although $\mathrm{NaCl}$ is an important component in both the artificial and natural seawater samples used in this work, it is likely that the presence of organics and other inorganic salts and the use of diverse generation mechanisms may lead to morphologies different to that of pure $\mathrm{NaCl}$ particles. Transmission Electron Microscope images of particles generated from artificial and natural seawater by bubble bursting have shown that the morphology of these particles differs from the well-known cubic shape of $\mathrm{NaCl}$ particles (Wise et al., 2009).

In our hygroscopicity experiments with the H-TDMA instrument we can consider that the particles are dry at the humidity for particle selection $(\mathrm{RH}<10 \%)$. Because of the high hygroscopicity of sea spray particles, some water is probably absorbed on the particles at the relative humidity for size selection in the DMA used for the size distribution and CCN measurements (32-42\% RH); however, it is not clear to what extent the water absorbed by the particles at this humidity can induce a change to spherical shape. Although the onset of particle morphology change for sea spray particles has been observed to occur at $45 \% \mathrm{RH}$, particle rounding does not take place until 65\% RH is reached (Wise et al., 2009). In order to account for the uncertainty in the morphology of the particles produced by the different generators employed in this work, correction factors in the range from spherical $(\chi=1)$ to cubic shape $(\chi=1.08)$ are applied, with the averaged data evaluated with a factor of $\chi=1.04$.

\section{Results}

\subsection{Bubble spectrum measurements}

\subsubsection{Comparison of bubble-bursting generators}

Investigations on the study of the number and size of sea spray particles produced by individual bubbles have demonstrated that the relative contribution of jet and film drops to the aerosol production depends on the characteristics of the parent bubble size distribution (Spiel, 1997; Wu, 2002). Laboratory reproduction of the oceanic bubble spectrum would therefore be relevant for the generation of a representative marine aerosol. In order to test the ability of the selected bubble-bursting methods for simulating the real oceanic bubble spectrum, the size distribution of the bubbles generated in artificial seawater was experimentally determined.

The bubble size distribution obtained for the water recirculation system, illustrated in Fig. 2, is characterized by a peak within the $40-80 \mu \mathrm{m}$ diameter range followed by a less pronounced mode at $400-600 \mu \mathrm{m}$. The use of increasing water recirculation flow rates caused an increase in the bubble number within the whole size range as a result of a higher air entrainment in the water bulk; however, the shape of the distribution was preserved. The bubble spectra produced by the glass frit and diffuser are shown in Fig. 3. A bimodal distribution characterized by a narrow peak at $30-40 \mu \mathrm{m}$ bubble diameter and a second broad mode between 200 and $300 \mu \mathrm{m}$ was generated by the aquarium diffuser, while a multimodal spectrum was obtained for the glass sintered filter. 


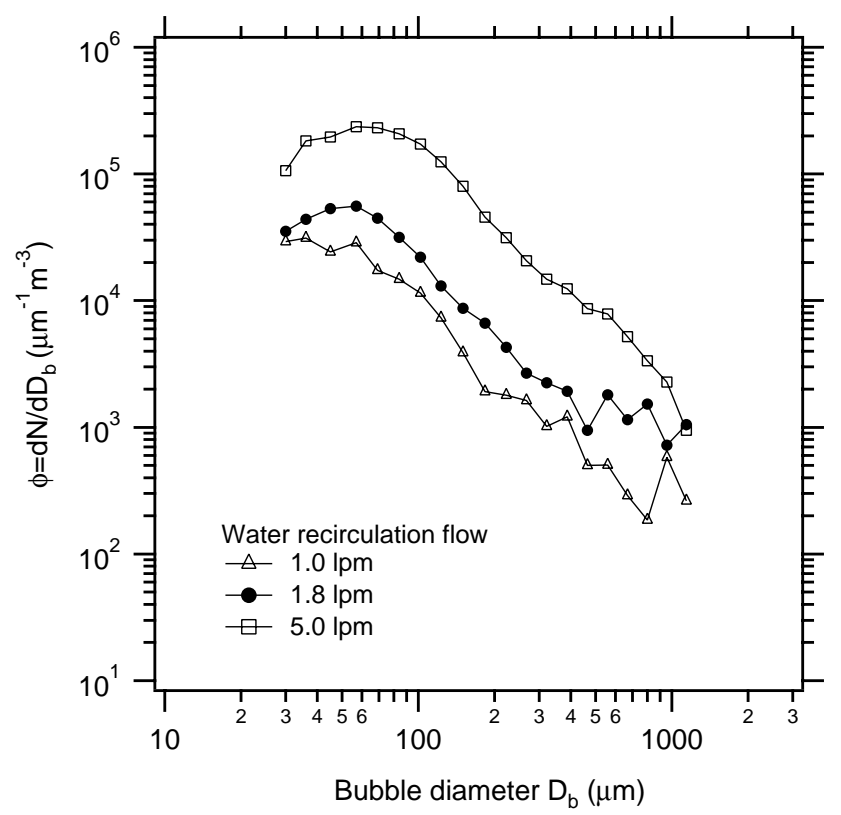

Fig. 2. Bubble population distribution versus bubble diameter for the plume generated by the plunging-water jet system at different water recirculation flows.

A common characteristic of these distributions is that they present a high number of bubbles larger than $100 \mu \mathrm{m}$, which is in agreement with previous observations of spectra produced by glass frits (Mårtensson et al., 2003; Leifer et al., 2003; Sellegri et al., 2006). The differences in the shape of the bubble spectra generated by the diverse systems indicate that different particle production rates and size distributions should be expected from the several aerosol generators used.

Oceanic bubble measurements typically peak in a range from 40 to $80 \mu \mathrm{m}$ diameter, with the bubble number decreasing with size following a power-law scaling with an exponent which varies between 0.8 and 5 (Deane and Stokes, 2002; Leeuw and Leifer, 2002). The existence of a second peak at $400-600 \mu \mathrm{m}$ has also been reported in oceanic spectra in open ocean (de Leeuw and Cohen, 2002). The oceanic bubble spectrum power-law scaling has been proven to be related to the life cycle of bubbles generated by breaking waves (Deane and Stokes, 2002). The lifetime of wavegenerated bubbles is divided into two phases. The first stage takes place as the fluid jet is entrained in the water, and is known as the acoustically active phase. Once bubble production is finished, the formed bubble plume becomes acoustically quiescent and it evolves under the effect of turbulent diffusion, advection, buoyant degassing and dissolution (Deane and Stokes, 2002). Deane and Stokes (2002) studied the evolution of bubble plumes below whitecaps after breaking wave events. They reported an increasing value of the bubble spectrum power-law exponent with time due to the bubble plume transition from the acoustic to the quiescent state. Oceanic measurements below breaking waves during the acoustic phase present a higher number of large bubbles than measurements under quiescent conditions. The bubble spectrum power law exponents at acoustic conditions range from 0.8 to 1.9 (Deane and Stokes, 2002). On the other hand, oceanic measurements in quiescent plumes which had evolved from initial acoustic primary plumes present higher power scaling law exponents, with values from 2.5 to 5 . The evolution of bubble plumes by breaking waves has also been studied in wind-wave channels (Leifer and de Leeuw, 2006). Leifer and de Leeuw (2006) consider the occurrence of four stages in the life cycle of bubble plumes formed by breaking waves: formation, injection, rise, and senescence. Besides the time evolution of bubble plumes, spatial variations have also been found in oceanic bubble spectra (Bowyer, 2001; Terril et al., 2001; Baldy, 1988). Bubble concentrations have been observed to increase toward the surface accompanied by a decrease in the power law exponent (Bowyer, 2001; Baldy, 1988).

A number of observations of oceanic bubble spectra, along with the experiments from the bubbling systems obtained in this work are illustrated in Fig. 4. Oceanic plumes below breaking waves have been represented with measurements for the plunging jet system and spargers at the tank centre in Fig. 4a, while oceanic quiescent plumes have been plotted with our plunging water jet measurements at $110 \mathrm{~mm}$ from the impingement point in Fig. 4b. The shape of the bubble spectrum produced by the plunging water jet system is in good agreement with the oceanic spectrum power-law profile. The power-law exponent values for this generator at the tank centre and at $110 \mathrm{~mm}$ from the impingement point are within the range expected in acoustic and quiescent conditions, respectively. The comparison presented in this figure indicates that the bubble distribution generated by the plunging-water jet system is more consistent with the oceanic measurements than those produced by the other bubbling systems, since the typical power-law profile of the real distribution is closely resembled. This finding is consistent with previous measurements reported by Leifer et al. (2003) and Sellegri et al. (2006) of bubble spectra generated by water impingement and aerators inmersed in seawater.

\subsubsection{Model bubble plume evolution}

We used a laboratory system that reproduces the physics of bubble formation (i.e. water impingement) for an analysis of the spatial variation of the bubble plume and its evolution, to explore whether there is any correlation in the behavior of the laboratory plumes and those in real conditions. To this end, the spatial distribution of the bubble population in the plunging-water jet system was characterised by measuring the bubble spectrum at different positions in the tank, at a constant depth of $4 \mathrm{~cm}$ below the water surface. Fields of bubble number and mean bubble size obtained from this analysis are depicted in Fig. 5a. The highest bubble 

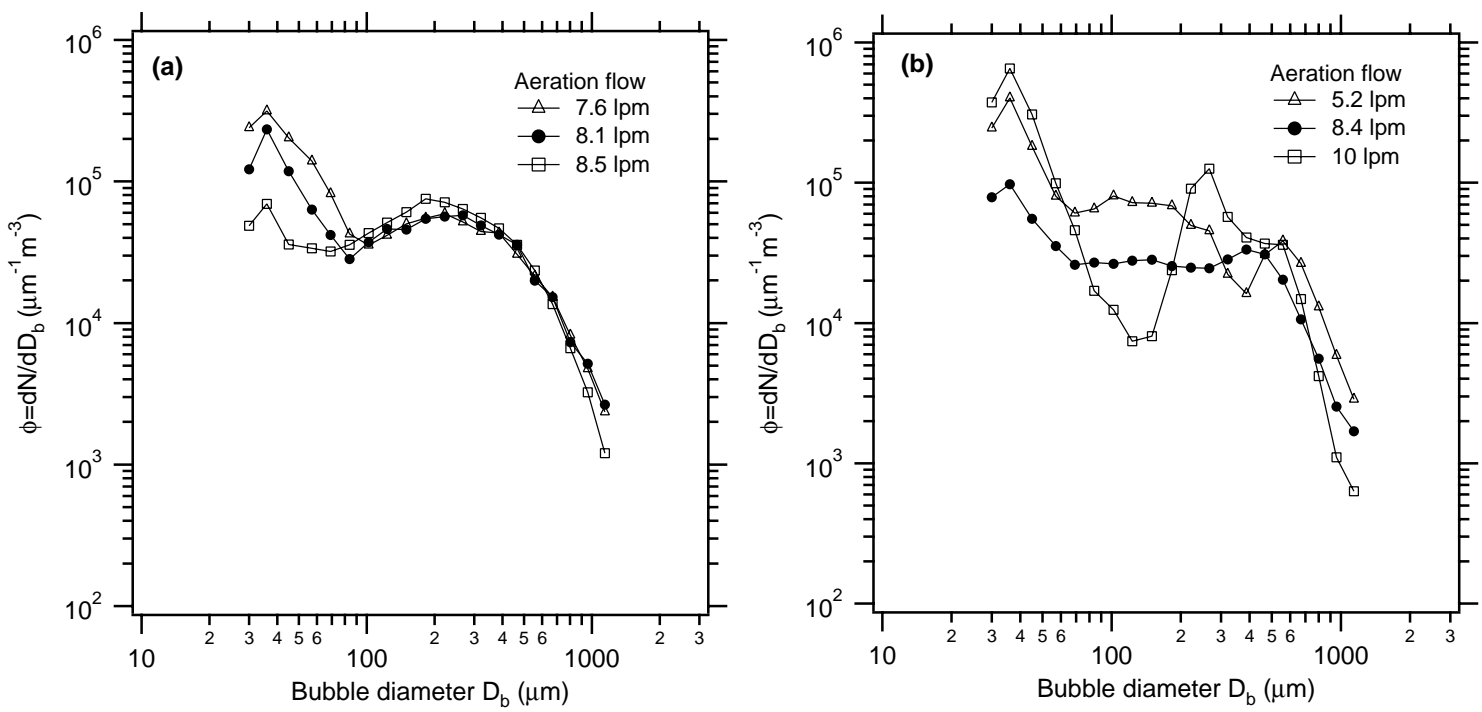

Fig. 3. Bubble population distribution versus bubble diameter for the plume generated by the (a) aquarium diffuser and (b) glass sintered filter at different aeration flows.
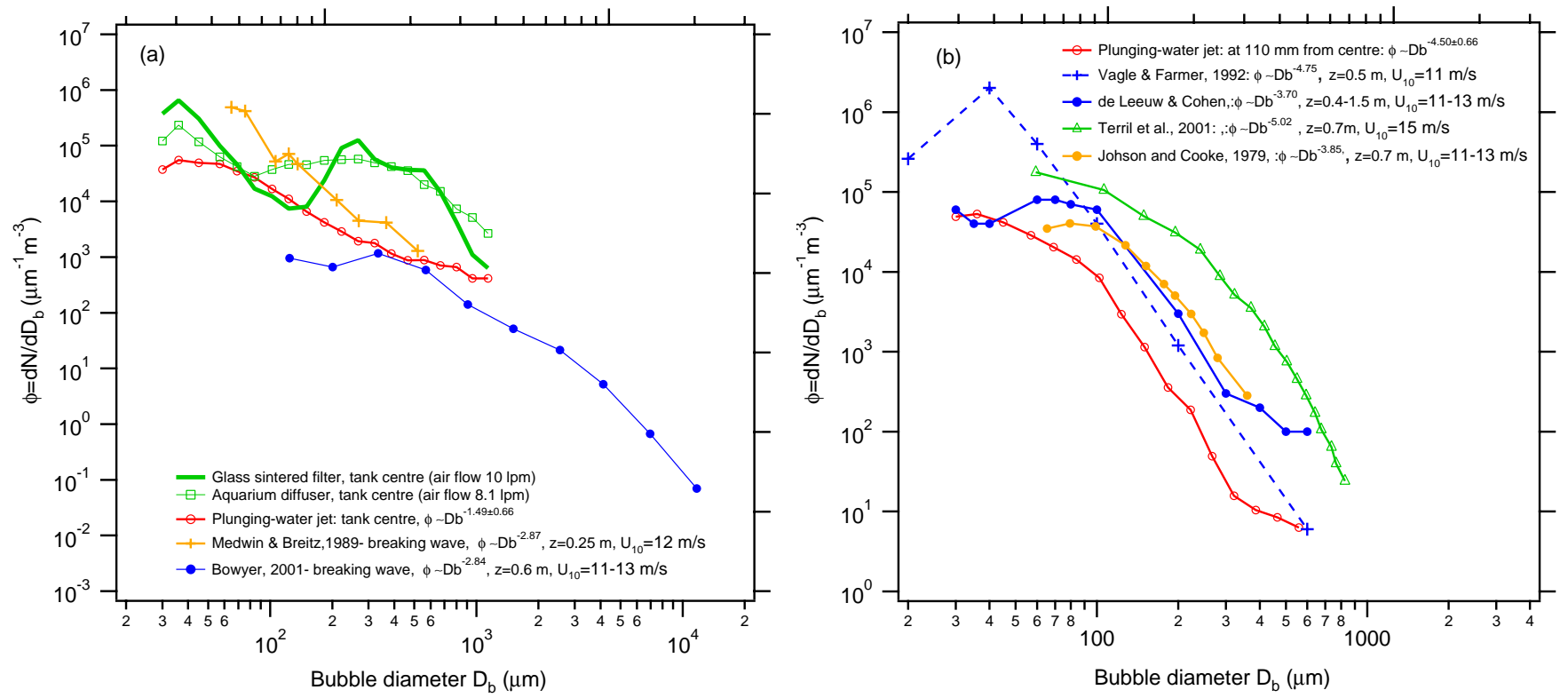

Fig. 4. Comparison between (a) bubble spectra obtained in the tank centre for the plunging-water jet system and spargers in this study and oceanic bubble spectra below breaking waves and (b) bubble spectra measurements at $110 \mathrm{~mm}$ from the impingement point in the water jet system and quiescent oceanic bubble spectra. ( $z=$ depth, $U_{10}=$ wind speed at $10 \mathrm{~m}$ above the surface).

concentrations and the large bubbles appear to be concentrated near the impingement region, while the bubble number and mean size are reduced as the sampling point is displaced from the plunging area. Figure 5b shows the spectrum of bubble plumes at different distances from the impinging point. A reduction in the number of bubbles with size larger than $100 \mu \mathrm{m}$ and a shift of the peak of the distribution to smaller sizes are observed as the distance from the water jet is increased. These trends account for the reduction in the number and size observed in the bubble spectrum field data in Fig. 5a. In these measurements the power-law exponent increases gradually as the sampling point is displaced from the impingement region, where it presents a value of 1.49 , to $110 \mathrm{~mm}$ from the tank centre, where the exponent value is 4.5 . The value of the power-law exponent at the impingement area is in good agreement with observations near the formation region (Deane and Stokes, 2002). Likewise, the power-law exponent of the bubble spectrum obtained at 

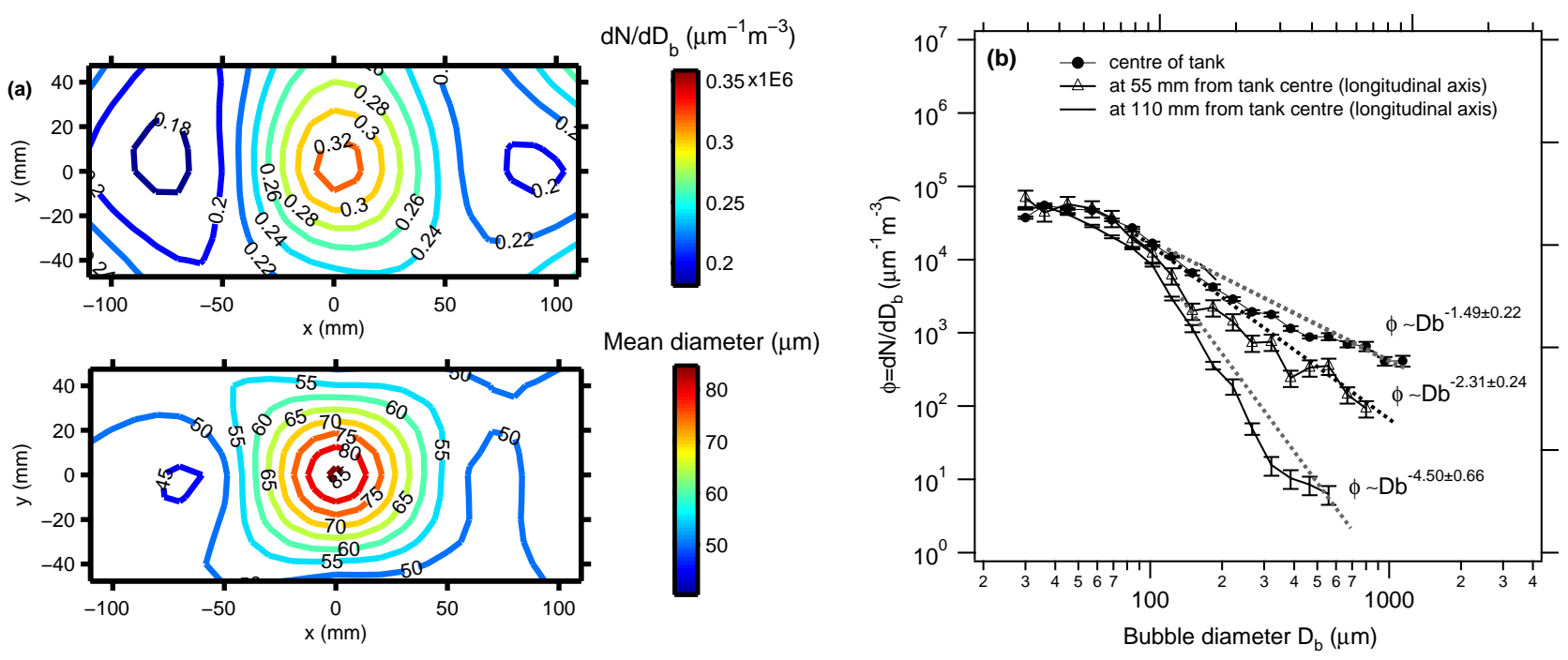

Fig. 5. (a) Spatial distribution of total number and mean size of bubbles generated by the plunging-waterjet system (1.8 $1 \mathrm{pm}$ water recirculation flow) and (b) bubble spectra at impingement, $55 \mathrm{~mm}$ and $110 \mathrm{~mm}$ from the tank centre. Error bars indicate the variability of the measurements as $\pm 1 \sigma$ standard deviation.

$110 \mathrm{~mm}$ from the impinging zone is comparable to those of bubble spectra measured in oceanic quiescent plumes, as was illustrated in Fig. 4. Spatial evolution has been observed in field measurements of bubble spectrum at different distances from the breaking wave zone at the water surface (Bowyer, 2001). These correspondences indicate that the bubble spectrum created below the plunging-water jet represents a bubble plume in the acoustic stage, in which a continuous generation of bubbles occurs, whilst measurements outside the plunging area correspond to bubble populations originated from a nascent bubble plume which has gradually evolved from acoustic to quiescent conditions.

\subsection{Aerosol size distribution}

Aerosol size distributions obtained from artificial seawater by using the different generation techniques are shown in Fig. 6. As the order of magnitude of particle production in the systems studied is considerably different, the results have been normalized to the total particle number for comparison purposes.

For a more accurate comparison of these multimodal curves, each size distribution was decomposed into an optimum number of lognormal modes by applying least square fitting to the experimental data, so that the total distribution results from the sum of the different lognormal modes. Four modes were found in the size distributions generated by $\mathrm{u}-$ sing the bubble-bursting techniques, while only two modes comprise the distribution of the atomized aerosol. The properties of the measured size distributions are summarized in Table 3. The submicron particle size distributions generated by the plunging-water jet system presents modes at 14,48 ,
124 and $334 \mathrm{~nm}$. The second to fourth lognormal modes in the aerosol distributions generated by the spargers peak at smaller sizes than those of the plunging-water jet aerosol, whereas only the glass sintered filter measurement shows a significant fourth lognormal mode at $250 \mathrm{~nm}$.

A foam of pseudo-stable bubbles, only observed when bubbling with the glass sintered filter and the plunging-water jet might be related to the formation of this fourth mode of larger particles. Furthermore, the higher significance of the fourth lognormal mode in the plunging-water jet measurement, with respect to the distributions generated by the other bubblers, could be associated with a mechanism particularly predominant in this system. A notable splashing, produced from the impact of the water jet on the water surface, was observed for the plunging jet system. This could be related to the formation of the fourth lognormal mode, directly, via the generation of particles as a result of splashing, or through an effect on the bursting of bubbles reaching the water surface. These observations are similar to findings by Sellegri et al. (2006). These authors found that the size distributions obtained by using a weir system were formed by three lognormal modes with modal sizes $\sim 45 \mathrm{~nm}, 112 \mathrm{~nm}$ and $300 \mathrm{~nm}$. The modal sizes of the second to third lognormal modes in the distribution of the aerosol generated by our plunging water jet system are in good agreement with the modal sizes reported by Sellegri et al. (2006). An additional similarity between our results and Sellegri et al. (2006) is the higher significance of the lognormal mode with modal size $\geq 300 \mathrm{~nm}$ in the water impingement system with respect to the size distributions of the aerosol generated by spargers. The formation of this lognormal mode has been suggested to be related to 

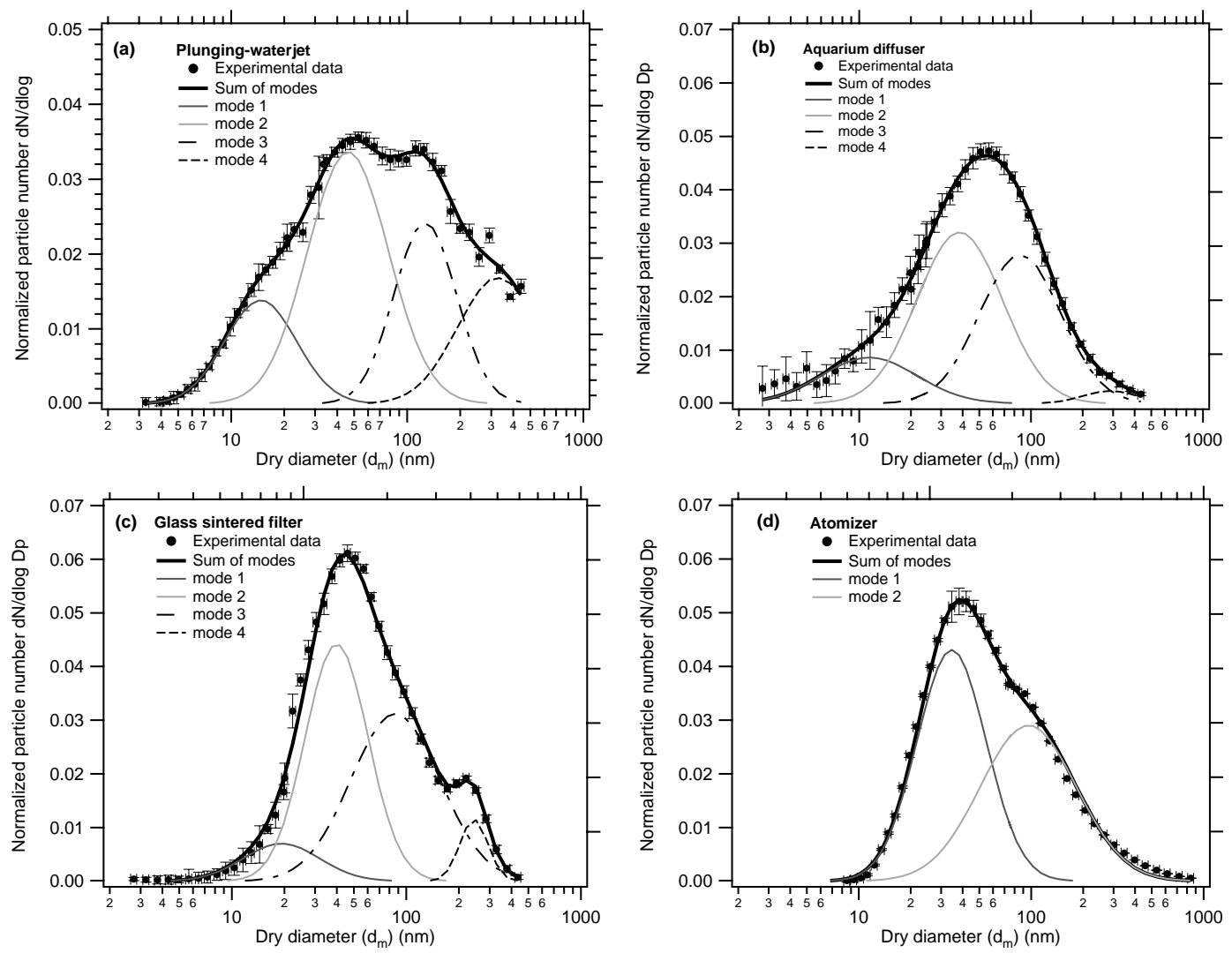

Fig. 6. Normalized particle size distributions of aerosols generated from artificial seawater by (a) the plunging-water jet system ( 8 water jets), (b) aquarium diffuser (8 $\mathrm{lpm}$ air flow), (c) glass sintered filter (5 lpm air flow) and (d) atomizer. A shape factor $\chi=1.04$ was applied to the presented data. Horizontal error bars indicate the uncertainty in the diameter selected by the DMA as function of the shape factor correction in the range from spherical $(\chi=1)$ to cubic $(\chi=1.08)$ shape. Vertical bars indicate the variability of the measurements obtained from 6 scans during $1 \mathrm{~h}$ period as $\pm 1 \sigma$ standard deviation.

Table 3. Characteristics of aerosol size distributions obtained from artificial seawater samples in this study in comparison with atmospheric marine aerosol measurements (Sellegri et al., 2006) ( $\mathrm{D}_{\mathrm{pg}}$, geometric mean diameter (shape factor $\chi=1.04$ for laboratory measurements); $\sigma_{g}$, geometric standard deviation; $N / N_{t}(\%)$, lognormal mode particle number to total number ratio).

\begin{tabular}{cccccccccccccc}
\hline & \multicolumn{3}{c}{ Mode 1 } & \multicolumn{3}{c}{ Mode 2 } & \multicolumn{3}{c}{ Mode 3 } & \multicolumn{3}{c}{ Mode 4 } \\
\hline & $\begin{array}{c}\mathrm{D}_{\mathrm{pg}} \\
(\mathrm{nm})\end{array}$ & $\sigma_{g}$ & $\begin{array}{c}N / N_{t} \\
(\%)\end{array}$ & $\begin{array}{c}\mathrm{D}_{\mathrm{pg}} \\
(\mathrm{nm})\end{array}$ & $\sigma_{g}$ & $\begin{array}{c}N / N_{t} \\
(\%)\end{array}$ & $\begin{array}{c}\mathrm{D}_{\mathrm{pg}} \\
(\mathrm{nm})\end{array}$ & $\sigma_{g}$ & $\begin{array}{c}N / N_{t} \\
(\%)\end{array}$ & $\begin{array}{c}\mathrm{D}_{\mathrm{pg}} \\
(\mathrm{nm})\end{array}$ & $\begin{array}{c}\sigma_{g} \\
N / N_{t} \\
(\%)\end{array}$ \\
\hline Multiple plunging-water jet system & 14 & 1.8 & 0.382 & 48 & 1.6 & 0.317 & 124 & 1.4 & 0.168 & 334 & 1.5 & 0.133 \\
Glass sintered filter & 20 & 1.7 & 0.089 & 41 & 1.5 & 0.452 & 87 & 1.8 & 0.417 & 250 & 1.2 & 0.041 \\
Aquarium diffuser & 12 & 1.9 & 0.130 & 37 & 1.8 & 0.50 & 87 & 1.7 & 0.348 & 286 & 1.4 & 0.015 \\
Atomizer & 35 & 1.6 & 0.530 & 100 & 1.9 & 0.462 & & & & & & \\
Field data (Sellegri et al., 2006) & 15 & 1.5 & 0.072 & 35 & 1.7 & 0.497 & 104 & 1.5 & 0.283 & 203 & 1.5 & 0.148 \\
\hline
\end{tabular}

forced bursting of pseudo-stable bubbles on the water surface induced by the splashing produced by water impingement (Sellegri et al., 2006).

The occurrence of different modes in the aerosol distributions could be the result of diverse bubble bursting scales. According to Leifer et al. (2000), in addition to bubble formation through air entrainment by breaking waves, bursting of initial bubbles can form secondary bubbles near the water surface. The bursting of these groups of secondary bubbles, in addition to the bursting of the primary bubbles, might contribute to the formation of the different modes comprising these particle size distributions. 

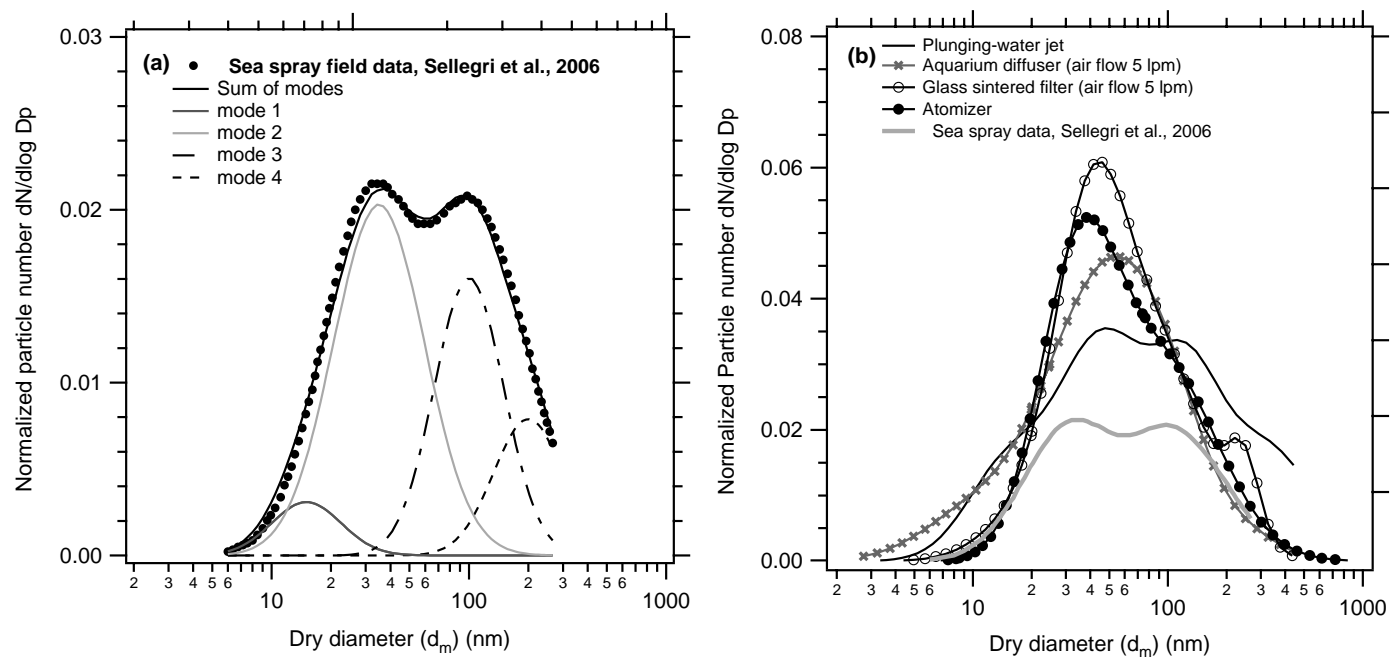

Fig. 7. (a) Normalized atmospheric sea spray size distribution from Sellegri et al. (2006) and (b) comparison of primary particle size distributions of aerosols generated from artificial sea water via bubble-bursting and atomization (shape factor $\chi=1.04$ ) and the atmospheric size distribution from Sellegri et al. (2006).

Figure 7 shows the size distributions obtained in this study along with a submicron atmospheric particle size distribution measured at the Mace Head Atmospheric Research Station under marine conditions by Sellegri et al. (2006). The atmospheric particle size distribution was measured in a month with low biological activity (January 2004), thus a low organic content is expected in these oceanic waters. Decomposition of the oceanic measurement into lognormal modes showed that the ambient size distribution also comprised four modes. Although Fig. 7b indicates some similarities between the shape of the atmospheric measurement and the primary distribution generated by our plunging-water jet system, it should be noted that comparison of primary and ambient aerosol cannot be made directly due to the presence in the ambient aerosol of components that originated from secondary processes and other aerosol sources, like non-sea salt sulphate aerosol from anthropogenic origin (Savoie et al., 2002). In addition, other factors such as water temperature can affect the characteristics of the particle size distribution generated. Our measurements were conducted at $\sim 20^{\circ} \mathrm{C}$ while the field data corresponds to seawater at $4{ }^{\circ} \mathrm{C}$. Laboratory experiments show evidence that a decrease in the water temperature leads to a reduction in the mean size of the emitted particles (Sellegri et al., 2006; Mårtensson et al., 2003).

From these experiments we conclude that the mechanism for aerosol production affects the shape of the particle size distribution and thus, in the intercomparison between different laboratory studies both the influence of the seawater sample and the particle production method should be taken into account.

\subsection{Hygroscopicity and CCN activity}

Hygroscopic growth in the humidity range from 50 to $95 \%$ RH was measured for $100 \mathrm{~nm}$ dry diameter particles generated from artificial seawater samples. Figure 8a shows the hydration behaviour of particles produced from artificial seawater using the different aerosol generation techniques, along with experimental and theoretical data for pure $\mathrm{NaCl}$.

The error bars on the plunging-waterjet curve are indicative of the uncertainty in the diameter selected by the DMA, calculated considering correction factors in the range from spherical $(\chi=1)$ to cubic shape $(\chi=1.08)$. A shape factor of $\chi=1.04$ was applied to the presented data. Although not included here for clarity, the same uncertainty range should be considered for all the experiments.

Without significant differences between the studied cases, observable water uptake already occurred at 50\% humidity, followed by a progressive growth with increasing $\mathrm{RH}$ and a substantial water uptake in the 70 to $80 \%$ humidity range. The characteristics of this humidogram are in agreement with observations of ambient marine aerosols (Winkler et al., 1972; Tang et al., 1997) and aerosols generated from artificial and natural seawater samples (Cziczo et al., 1997; Wise et al., 2009). The hygroscopic properties of sea spray particles are consistent with what is expected from a multicomponent aerosol system. The presence of salts of low deliquescence point, such as $\mathrm{MgCl}_{2}$, are considered to be responsible for the water uptake occurring at RH lower than that of $\mathrm{NaCl}$ (Cziczo et al., 1997), while the significant growth at $\sim 75 \% \mathrm{RH}$ is related to the total dissolution of $\mathrm{NaCl}$ crystals.

Natural filtered seawater samples, enriched with Thalassiosira rotula exudate at $512 \mu \mathrm{M}$ DOC concentration, were prepared to compare the behaviour of particles produced by 

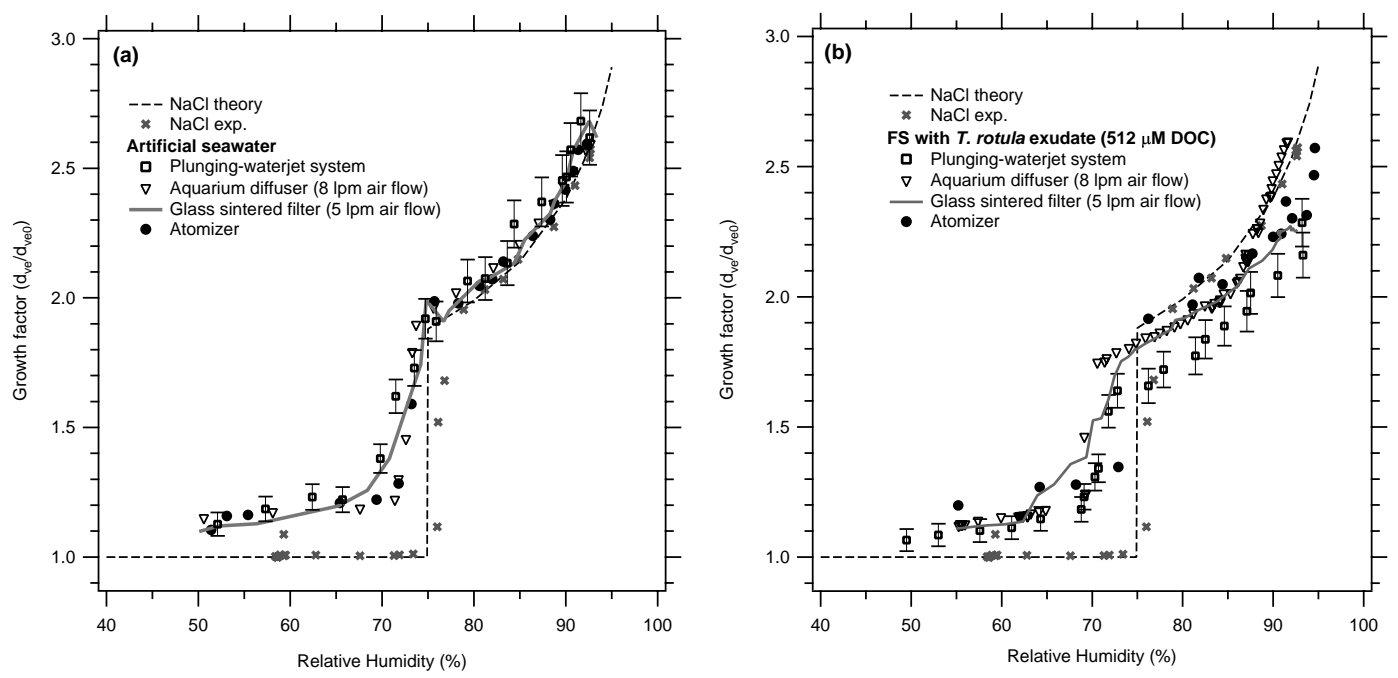

Fig. 8. Humidograms of $100 \mathrm{~nm}$ dry particles $\left(d_{m}\right)$ generated by bubble-bursting and atomization from (a) artificial seawater and (b) FS=filtered natural seawater enriched with Thalassiosira rotula exudate (512 $\mu \mathrm{M}$ DOC concentration). A shape factor $\chi=1.04$ was applied to the presented data. Error bars indicate the uncertainty in the diameter selected by the DMA as function of the shape factor correction in the range from spherical $(\chi=1)$ to cubic $(\chi=1.08)$ particles.

the different aerosol generators. Figure $8 \mathrm{~b}$ presents the hygroscopic growth of the particles generated from seawater containing algal exudate along with the theoretical and experimental curves for $\mathrm{NaCl}$. The existence of organic material in the sea spray particles suppresses the hygroscopic growth in comparison with the artificial seawater measurements in all cases, although the magnitude of the observed effects is dependent on the generation technique employed. The main differences between the humidograms are observed above $75 \% \mathrm{RH}$, with the plunging-water jet presenting the highest growth suppression. The rest of the cases show a similar behaviour up to $87 \% \mathrm{RH}$, above which the humidograms for the aerators and the nebulizer diverge. Wise et al. (2009) reported analogous findings to our results in their comparison of the morphological changes of growing sea spray particles generated from artificial and natural seawater using two different aerosol generators. These authors found that there were no differences in the hygroscopic properties of particles generated from organics-free artificial seawater by either atomization or foam-bubble bursting; however, they observed a difference in the onset of morphological change and rounding of particles produced by the two generators when using natural seawater.

The CCN activity of particles generated from artificial seawater and seawater containing organic exudate was characterized for dry particle diameters between 40 and $110 \mathrm{~nm}$. Critical supersaturations obtained from these experiments are shown in Fig. 9a, b, c, along with the theoretical curve for $\mathrm{NaCl}$. The horizontal error bars account for the uncertainty in the selection of the particle diameter by the DMA as a function of the particle shape, and the vertical error bars indicate the mean uncertainty in the determination of the critical supersaturation taken as $\pm 1 \sigma$ standard deviation. Although not included in all cases in Fig. 9a-c for clarity of presentation, the same uncertainty range should be considered for all the experiments.

Whereas the measurements with artificial seawater indicate no significant effects on the critical supersaturation with respect to the theoretical values for $\mathrm{NaCl}$, the presence of biogenic organics implies an increase in the critical supersaturation in all cases; however, the degree of this effect is dependent on the aerosol generation system employed. Relative variation in the critical supersaturation Sc with respect to the critical supersaturation for the case without organics presented in Fig. 9d shows a large effect for the atomization experiments, with a notable increase in the critical supersaturation with increasing particle size from $6 \%$ at $38 \mathrm{~nm}$ $\left(d_{v e}\right)$ to $43.8 \%$ at $96.3 \mathrm{~nm}\left(\mathrm{~d}_{\mathrm{ve}}\right)$. The change in the slope of the curve for the atomization measurements (Fig. 9b) suggests the occurrence of surface tension effects below $70 \mathrm{~nm}$ or organic component size fractionation.

The influence of organics on the critical supersaturation of particles generated in the bubble-bursting experiments showed little size dependence, with $17 \%$ and $11 \%$ averaged increase in the critical supersaturation, for the experiments with the plunging water jet and the porous bubblers, respectively. Although the presence of surface-active organic material in the particles would induce a reduction in the surface tension and, consequently, a decrease in the critical supersaturation according to the equilibrium Köhler theory, the observed increase in the critical supersaturation might be due to a dominance of the Raoult term because of the replacement 

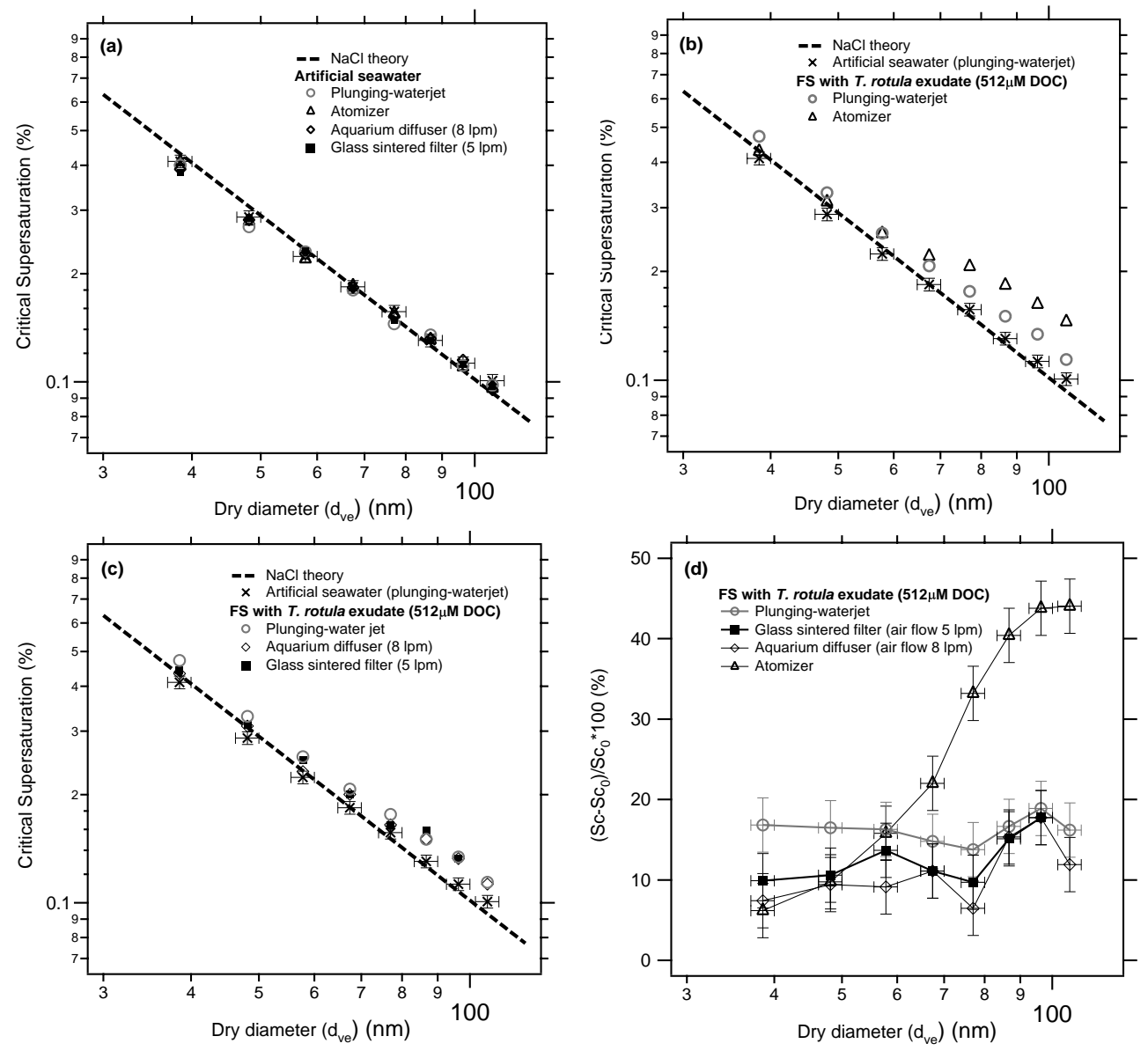

Fig. 9. Critical supersaturation as a function of particle diameter $\left(\mathrm{d}_{\mathrm{ve}}\right)$ for the aerosol generated from (a) artificial seawater and (b), (c) FS=filtered natural seawater enriched with Thalassiosira rotula exudate (512 $\mu \mathrm{M}$ DOC concentration), for the different aerosol generation techniques. (d) Relative variation in the critical supersaturation Sc with respect to the critical supersaturation for the case without organics $\mathrm{Sc}_{0}$ of aerosols generated from filtered natural seawater containing algal exudate. A shape factor $\chi=1.04$ was applied to the presented data. Horizontal error bars indicate the uncertainty in the diameter selected by the DMA as function of the shape factor correction in the range from spherical $(\chi=1)$ to cubic $(\chi=1.08)$ shape. Vertical bars indicate the mean uncertainty in the determination of the critical supersaturation taken as $\pm 1 \sigma$ standard deviation.

of inorganic salts by organic compounds and surface to bulk partitioning effects (Li et al., 1998; Sorjamaa et al., 2004). A detailed analysis of the influence of the marine biopolymers on the particles $\mathrm{CCN}$ behaviour is beyond the scope of this work and will be presented elsewhere. Nevertheless, it is clear that representative bubble-bursting and aerosol generation mechanisms must be used to simulate these effects.

\section{Considerations on the bubble path length and lifetime in bubble-bursting small-scale systems}

The discrepancies in the hygroscopicity and CCN activity of aerosols generated by the different systems used in this study suggest that the mechanism producing the particles and, probably, the specific operating conditions, influence the particles organics enrichment. The sea-water-to air transfer of surface active organic compounds has been shown to be related to the scavenging of organic matter by the rising bubbles, which is dependent on the bubble spectrum and the chemical properties of the material absorbed by the bubbles (Tseng et al., 1992). It has been hypothesized that marine surfactant scavenging by rising bubbles depends on the bubble path and that providing path lengths of the order of $1 \mathrm{~m}$ in laboratory systems implies replicating the oceanic bubbles lifetimes (Keene et al., 2007). On the other hand, Tyree et al. (2007) assumed that the lifetime of oceanic bubbles can been approximated to the order of wave periods (1-5s). In these previous works it has not been considered that the oceanic bubble lifetimes depend on the bubble size (Lewis and Schwartz, 2004) and on the interaction between bubbles at the high void fraction conditions in oceanic bubble swarms 
(Lamarre and Melville, 1991). In this section we will analyze this aspect by comparing the estimated lifetimes of bubbles generated by the systems employed in the present study and others in the literature with the expected lifetimes of oceanic bubbles.

To determine the velocity of bubbles produced in the laboratory systems we will assume that the bubbles generated by a vertical plunging water jet and spargers in seawater reach their terminal velocity rapidly after formation, as it has been shown that bubbles generated in solutions of $\mathrm{NaCl}$ and surfactants attain their terminal velocity in less than $1 \mathrm{~cm}$ (Krzan and Malysa, 2009). The rise velocity of isolated bubbles whose surface is covered with surfactants can be estimated as (Batchelor, 1967):

$U_{0}^{2}=\frac{4}{3} \frac{\mathrm{D}_{b}\left(\rho-\rho_{g}\right)}{\rho C_{\mathrm{d} 0}}$

$C_{\mathrm{d} 0}=\frac{12}{R e_{0}}\left(1+0.104 R e_{0}\right)$

where $U_{0}$ is the terminal rise velocity of the bubbles, $\mathrm{D}_{b}$ is the bubble diameter, $\rho$ is the density of the liquid, $\rho_{g}$ is the air density, $C_{\mathrm{d} 0}$ is the drag coefficient and $R e_{0}$ is the bubble Reynolds number.

The bubble rise velocity in bubble clouds is affected by hindrance and wake effects exerted by surrounding bubbles (Simonnet et al., 2007). In bubble clouds, wake effects are frequently compensated by hindrance effects and the terminal velocity of bubbles is defined as a function of the velocity of the isolated bubble and the global gas void fraction (Ribeiro and Mewes, 2007; Richardson and Zaki, 1954):

$U_{\mathrm{wj}}=U_{0}(1-\alpha)^{n-1}$

where $n$ is the Richardson-Zaki exponent, which is a function of the Reynolds number, and $\alpha$ is the void fraction. For the determination of the Richardson-Zaki exponent we will use the parameterization of Richardson and Zaki (1954), which has been shown to be valid for bubble swarms for $R e_{0}<300$ and Morton number $<3.910^{-10}$ (Sankaranarayanan et al., 2006).

Void fractions generated by plunging water jets with the dimensions used in this work are expected to be $<0.05$ (Chanson et al., 2004), thus we will assume that the velocity of the bubbles generated by the plunging water jet is equal to the terminal velocity of an isolated bubble.

Several flow regimes as a function of the superficial gas velocity are defined in the behavior of bubbly flows generated by injecting air through spargers (Ruzicka et al., 2003). In the homogeneous regime, non-coalescing and almost spherical bubbles are generated continuously from the orifices of the porous plate. For low flow conditions, in the stable plate phase of the homogeneous regime, the void gas fraction increases linearly with the superficial gas velocity because of negligible hindrance effects between bubbles (Ruzicka et al.,
2003). The superficial gas velocity in our measurements with the glass sintered filter is $0.03 \mathrm{~m} \mathrm{~s}^{-1}$, thus we can assume that the flow conditions correspond to the linear section of the homogeneous regime (Ribeiro and Mewes, 2007). This flow regime is characterized by the formation of in-line trailing bubbles, whose motion is affected by wake effects which cause the train of bubbles to rise faster than single bubbles in still water (Zhang and Fan, 2003). The ratio between the rise velocity of a trailing bubble $U_{\mathrm{gf}}$ and the velocity of an isolated bubble $U_{0}$ is given by Zhang and Fan (2003):

$U_{\mathrm{gf}} / U_{0}=1+\frac{C_{\mathrm{d} 0}}{2}\left[1-\exp \left(\frac{R e_{0}}{x / \mathrm{D}_{b}}\right)\right]$

where $x$ is the distance between the trailing bubbles. The distance between the bubbles can be estimated from the number of bubbles in the bubble column generated from a pore on the plate, which depends on the air flow through the porous media:

$x=\frac{h\left(1-\mathrm{D}_{b} N_{b}\right)}{h N_{b}-1}$

$N_{b}=\frac{Q_{p}}{V_{b} U_{\mathrm{gf}}}$

where $Q_{p}$ is the mean air flow per pore, $N_{b}$ is the number of bubbles per unit length in the bubble column over a pore, $V_{b}$ is the bubble volume, and $h$ is the distance from the porous plate to the water surface. The mean air flow per pore is determined as $Q_{p}=Q_{\text {air }} A_{p} /(A \varepsilon)$, where $Q_{\text {air }}$ is the total flow through the plate, $A$ is the area of the porous plate, $\varepsilon$ is the glass frit porosity, and $A_{p}$ is the mean pore area. We will adopt the definition of trailing bubble rise velocity indicated by Eq. (4) to calculate terminal velocities of bubbles generated by the glass sintered filter $\left(U_{\mathrm{gf}}\right)$ in the conditions of our study.

Figure 10 shows the ratios of velocity and lifetimes of bubbles generated by our plunging jet system and the glass frit at two different bubbling air flows. A case with equal bubble path lengths $\left(z_{\mathrm{gf}} / z_{\mathrm{wj}}=1\right.$, with $z=$ bubble path and subscripts $\mathrm{gf}=$ glass frit and $w j=w a t e r j e t)$ and bubble path ratio as the one used in the experiments $\left(z_{\mathrm{gf}} / z_{\mathrm{wj}}=5 \mathrm{~cm} / 7 \mathrm{~cm}=0.71\right)$ are included to show the sensitivity of the bubble lifetime to this factor. The representation shows that the velocity of bubbles with sizes $<200 \mu \mathrm{m}$ is higher and, hence the lifetime lower, for the glass frit than for the plunging water jet, as a result of wake effects. This difference occurs in the size range where $80-90 \%$ of the bubble population is found (Fig. 10, bubble spectrum curves). Although the air flow through the glass frit affects the velocity and lifetime of bubbles, the results are critically dependent on the bubble path length.

The bubble lifetimes calculated by using Eqs. (1) to (6) for the multiple water jet system $(7 \mathrm{~cm}$ bubble path) and the glass frit $(5 \mathrm{~cm}$ bubble path) are illustrated in Fig. 11, along with the mean residence times indicated in the works of Tyree 


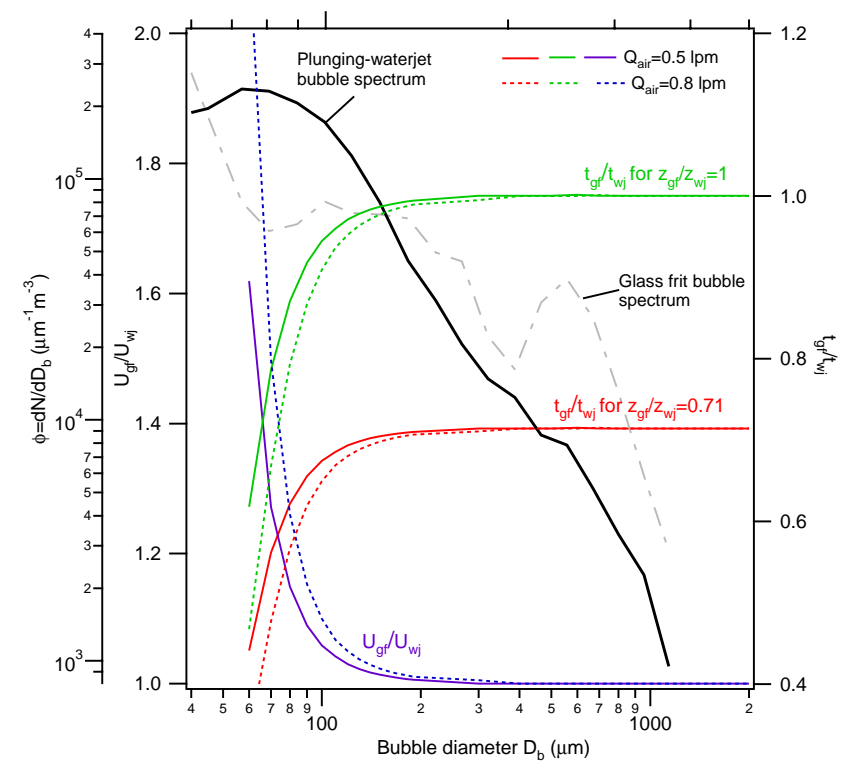

Fig. 10. Glass frit to plunging-water jet bubble rise velocity ratio $\left(U_{\mathrm{gf}} / U_{\mathrm{wj}}\right)$ and residence time ratio $\left(t_{\mathrm{gf}} / t_{\mathrm{wj}}\right)$ for two different aeration flows through the glass frit and bubble path ratios $z_{\mathrm{gf}} / z_{\mathrm{wj}}=1$ and 0.71 . Bubble population distributions generated by the glass frit (5.2 lpm air flow) and the single plunging-water jet system (5 lpm water flow) are included for comparison.

et al. (2007) (32-39.5 $\mathrm{cm}$ bubble path, mean bubble diameter $=230 \mu \mathrm{m})$ and Keene et al. $(2007)(100-130 \mathrm{~cm}$ bubble path, mean bubble diameter $=400 \mu \mathrm{m})$.

For comparison, the lifetime of oceanic bubbles, calculated using the equations for bubble swarms (1) to (3), and considering characteristic cloud residence depths of $0.5 \mathrm{~m}$, $1 \mathrm{~m}$ and $1.5 \mathrm{~m}$, have also been included in Fig. 11. In this calculation only hindrance effects are considered, as bubble wake effects in bubble clouds are compensated by hindrance in the size range of oceanic bubbles (diameter $<2 \mathrm{~mm}$ ) (Simonnet et al., 2007). The considered cloud residence depths, defined as the depth where the majority of bubbles reside, correspond to wind speeds of $4.6 \mathrm{~m} \mathrm{~s}^{-1}, 5.8 \mathrm{~m} \mathrm{~s}^{-1}$ and $6.9 \mathrm{~m} \mathrm{~s}^{-1}$, respectively, as derived from parametrizations obtained from oceanic measurements by Graham et al. (2004). Although at moderate and high wind speeds conditions, cloud residence depths are frequently of the order of $1 \mathrm{~m}$ and higher (Graham et al., 2004), we have evaluated a case at $0.5 \mathrm{~m}$ depth in order to include a conservative case at low wind speed conditions (Graham et al., 2004). For the calculations we have considered a void fraction of 0.2 , as in breaking wave events a minimum void fraction of 0.2 near the water surface is expected (Lamarre and Melville, 1991). Although we have analyzed the bubble size range above $60 \mu \mathrm{m}$, it should be noted that the critical bubble diameter (i.e. diameter below which bubbles reduce their size and dissolve before reaching the surface) is $80 \mu \mathrm{m}$ and $120 \mu \mathrm{m}$
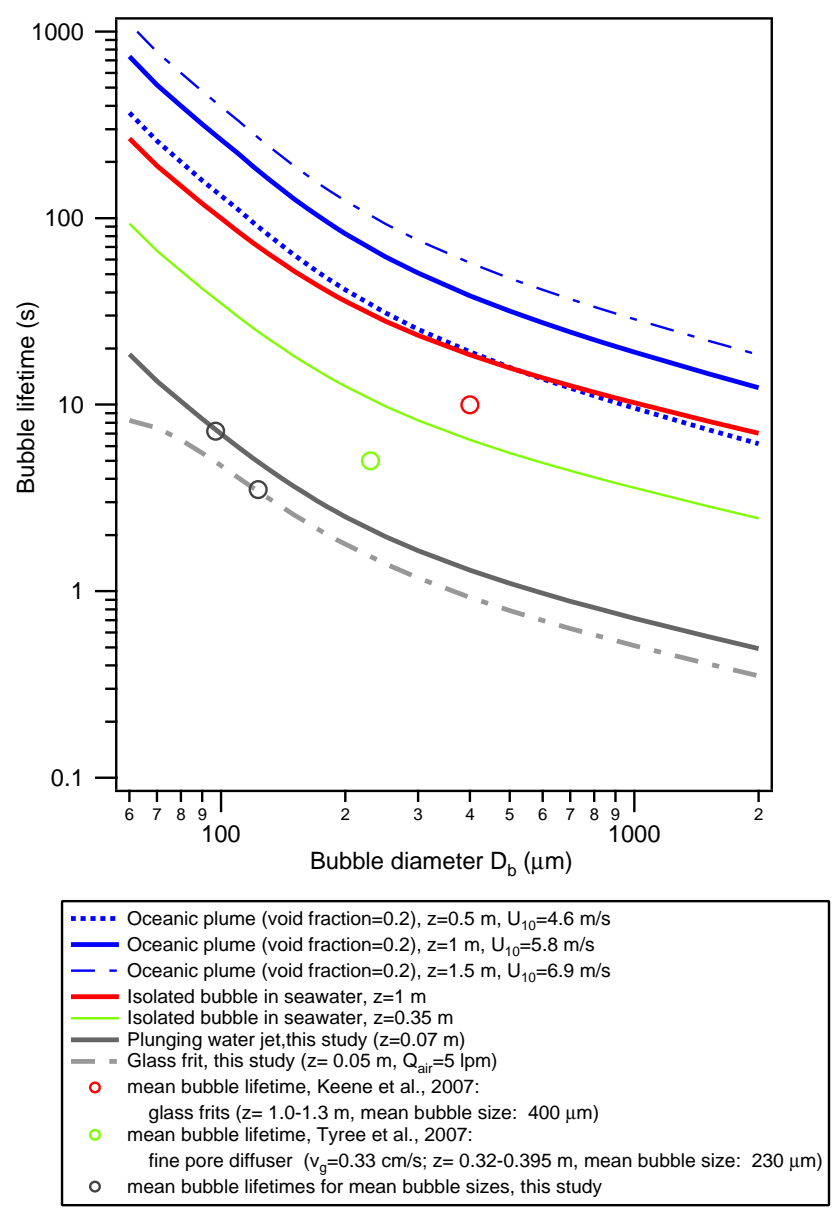

Fig. 11. Comparison of estimated lifetimes of bubbles generated by the plunging-water jet system and the glass sintered filter in this study with lifetimes reported by Keene et al. (2007) and Tyree et al. (2007), and oceanic plume lifetimes at $4.6 \mathrm{~m} \mathrm{~s}^{-1}, 5.8 \mathrm{~m} \mathrm{~s}^{-1}$ and $6.9 \mathrm{~m} \mathrm{~s}^{-1}$ wind speeds at a breaking wave event ( $z=$ bubble path, $U_{10}=$ wind speed at $10 \mathrm{~m}$ above the surface). Lifetimes of isolated bubbles at $1 \mathrm{~m}$ and $0.35 \mathrm{~m}$ depths are included for comparison.

for initial depths of $0.5 \mathrm{~m}$ and $1.5 \mathrm{~m}$, respectively (Lewis and Schwartz, 2004). Above these critical sizes, the change in the bubble diameter from $\leq 1-1.5 \mathrm{~m}$ depth to the surface is $<10 \%$ (Lewis and Schwartz, 2004), thus, we will assume that the bubble size is not modified on the way to the surface. Although bubbles below the critical size dissolve before reaching the surface, they also contribute to the transport of surface-active material to the subsurface region before dissolution. Hence, we have included the bubble size range down to $60 \mu \mathrm{m}$ diameter for the analysis.

Our calculations for oceanic lifetimes yield residence times from $6 \mathrm{~s}$ for bubbles with $2 \mathrm{~mm}$ diameter to $3 \mathrm{~min}$ for $80 \mu \mathrm{m}$ size at $4.6 \mathrm{~m} \mathrm{~s}^{-1}$ wind speed $(0.5 \mathrm{~m} \mathrm{depth})$, and from $12 \mathrm{~s}$ for bubbles with $2 \mathrm{~mm}$ diameter to $7 \mathrm{~min}$ for $80 \mu \mathrm{m}$ diameter, at a wind speed of $5.8 \mathrm{~m} \mathrm{~s}^{-1}(1 \mathrm{~m} \mathrm{depth})$. This calculation is consistent with measurements which indicate 
that oceanic bubble clouds are long lasting and present lifetimes at breaking wave events in field conditions on the order of minutes (Hwang and Teague, 2000; Lamarre and Melville, 1994; Johnson, 1986).

According to our analysis, none of the compared works replicate the oceanic bubble lifetimes. Specifically, in our study, it would require a tank depth of $\sim 3 \mathrm{~m}$ in the experiments with the glass frit, to achieve lifetimes representative of oceanic bubbles $>80 \mu \mathrm{m}$ at $1 \mathrm{~m}$ cloud residence depth. In the work of Keene et al. (2007), considering their mean bubble size, their tank would require a path length of 2-2.6 m to achieve the bubble lifetimes at low wind speed conditions and further extension to $4-5.2 \mathrm{~m}$ for replicating bubble lifetimes characteristics of $1 \mathrm{~m}$ cloud residence depth. Extension of the laboratory systems geometry to dimensions of this order imply operational limitations, particularly, when a limited amount of seawater sample is available.

Calculations of rise time for isolated bubbles (void fraction $=0$ ) at $1 \mathrm{~m}$ and $0.35 \mathrm{~m}$ depth have been included in Fig. 11 for comparison with Keene et al. (2007) and Tyree et al. (2007). The calculated isolated bubble rise times are consistent with the parametrization of Lewis and Schwartz (2004), which yields lifetimes from $9 \mathrm{~min}$ for $60 \mu \mathrm{m}$ bubble diameter to $5.7 \mathrm{~s}$ for $2 \mathrm{~mm}$ bubble size, for isolated bubbles in seawater with absorbed surfactants at $1 \mathrm{~m}$ depth. These rise times are increased in oceanic conditions due to hindrance effects existing in oceanic bubble swarms. Keene et al. (2007) and Tyree et al. (2007) experimental data indicate that the bubbles produced in their simulations are faster than isolated bubbles at $1 \mathrm{~m}$ and $0.35 \mathrm{~m}$ depth, respectively. This is indicative of low void fractions, characteristic of the stable plate phase in the homogeneous regime (this is clearly the case of Tyree et al. (2007), given their low superficial gas velocity), and significant wake effects at the operating conditions of these two studies.

Our comparison indicates that providing bubble paths of the order of $1 \mathrm{~m}$ in systems with glass frits as bubble generators does not imply reaching the oceanic bubble lifetimes, as the bubble motion in seawater depends on the bubbles size, void fraction and interaction between bubbles. Large rapid bubbles are usually produced by glass frits and wake effects at low void fractions in these type of systems can accelerate the motion of the produced bubbles. The use of spargers in the heterogeneous flow regime (i.e. large superficial gas velocities) would increase the void fraction and this could retard the bubble motion by hindrance (Ruzicka et al., 2003). This, however, would imply the production of increasing bubble sizes, less representative of oceanic bubbles, which would also lead to high mean bubble velocities. Hence, it is not clear if this flow regime would be effective for replicating the realistic bubble lifetimes and bubble spectrum.

The shallowness of plumes generated by small-scale plunging water jets systems as the one used in our study and others in the literature (Cipriano and Blanchard, 1981; Sellegri et al., 2006; Hultin et al., 2009) is a limitation imposed by the reduced inertial forces linked to plunging water jets of small dimensions. Available evidence suggests that the optimum system to reach the oceanic bubble lifetimes would be the generation of a large-scale plunging water jet in large volume tanks (>1001) as those employed by Facchini et al. (2008). This would allow the recirculation of high water flows (e.g. $20 \mathrm{lpm}$, Facchini et al., 2008) and the generation of deep plumes with high speed water jets (e.g. $>6 \mathrm{~m} \mathrm{~s}^{-1}$, Chanson et al., 2002) and thus, produce bubble plumes with depth penetrations $>0.5 \mathrm{~m}$ and high void fractions which retard the bubbles motion to the surface. These high speed jets can be produced by adjusting the nozzle diameter and height over water. As both the void fractions and the size of the bubbles generated by large scale plunging jets are expected to be representative of those of oceanic plumes (Chanson et al., 2004), the generation of plume depths $>0.5 \mathrm{~m}$ by a plunging water jet of these characteristics would ensure producing bubbles with lifetimes of the order of those in real plumes. This type of generator is, nevertheless, only useful when large amounts of sample are available, thus they are appropriate for in situ measurements with seawater. Due to the characteristics of our experiments, specifically regarding the limitations in the production of organic-enriched seawater with phytoplankton cultures, this type of large experimental system is not suitable for our study. Nevertheless, within this limitation, physical models of reduced dimensions have been demonstrated to be useful for studying the process of formation and evolution of oceanic bubble plumes and aerosol properties on a scaled basis (Leifer et al., 2007; Cipriano and Blanchard, 1981; Sellegri et al., 2006; Hultin et al., 2009). Implications derived from the limited lifetime in the laboratory systems, regarding the adsorption of organics by rising bubbles, are analyzed in the next section.

\section{Adsorption kinetics of marine surfactants on rising bubbles}

The reduced bubble lifetimes in small-scale systems, compared with the real conditions, might imply limitations in the adsorption of surfactants on the rising bubbles and, thus on the bubble and particles organic enrichment. For the case of bacteria adsorption on rising bubbles it has been found that the bubbles enrichment is dependent on the bubble rising distance (Blanchard, 1964). On the other hand, for the case of surface-active material, theoretical and experimental analysis have shown that the adsorption equilibrium of cationic surfactants (CTAB) on rising bubbles is achieved instantaneously (Morgan et al., 1992), which implies that adsorption is not limited by the transport of surfactants to the bubble surface.

In order to explore the adsorption of marine surface-active compounds on rising bubbles, in this section we analyze theoretically the evolution of the surface excess of surfactant at the interface of a bubble rising in a $T$. rotula algal exudate 
solution. For the analysis we will use the approach employed by Morgan et al. (1992), which is based on the boundary layer theory for bubble adsorption developed by Levich (1962). This approach considers mass transport by convection induced by the hydrodynamic flow and diffusion from the subsurface in equilibrium with the bulk solution to the bubble surface. According to Levich (1962), the diffusion boundary layer around a bubble is defined as the region in which mass transport by diffusion is more important than convection. Considering the diffusive flux equal to the convective flux around the bubble, the thickness of such boundary layer is defined by (Morgan et al., 1992):

$\delta=\left(\frac{D \mathrm{D}_{b}}{2 U}\right)^{1 / 2}$

where $D$ is the diffusion coefficient, $\mathrm{D}_{b}$ is the bubble diameter and $U$ is the bubble rise velocity. The diffusion coefficient $\left(\mathrm{cm}^{2} \mathrm{~s}^{-1}\right)$ for large organic molecules in water can be calculated by using the Stokes-Einstein Eq. (Young et al., 2003):

$D=9.96 \cdot 10^{-8} \frac{T}{\mu_{w} \bar{V}_{\text {org }}^{1 / 3}}$

where $T$ is the temperature $(293 \mathrm{~K}), \mu_{w}$ is the water viscosity (cP) and $\bar{V}_{\text {org }}$ is the molar volume of the organic compound. The molar volume was estimated by using a molecular weight of $1.99 \mathrm{kDa}$, value derived from fitting the virial equation of state to the surface pressure-molecular area isotherm of T. rotula exudate (Fuentes et al., 2010). The molecular weight employed is consistent with the molecular mass value of $2.38 \mathrm{kDa}$, corresponding to the phytoplankton biomass average elemental stoichiometry defined as $\mathrm{C}_{106} \mathrm{H}_{171} \mathrm{O}_{42} \mathrm{~N}_{16} \mathrm{PS}_{0.3} \mathrm{Mg}_{0.05}$ (Fraga, 2001) and within the range of mean molar mass of marine organics extracted from natural seawater samples (Pogorzelski and Kogut, 2001a). A density of $1550 \mathrm{~kg} \mathrm{~m}^{-3}$, which is the average density of humic like substances (Dinar et al., 2006) was used for the calculation.

Since convection effects dominate beyond the boundary layer thickness, the concentration at and beyond the boundary layer may be taken to be constant and equal to the bulk concentration. The surface excess $\Gamma$ change can be expressed as a function of flux to the interface by considering Fick's law as (Morgan et al., 1992):

$\frac{\partial \Gamma}{\partial t}=\frac{D\left(c_{0}-c_{s}\right)}{\delta}$

where $c_{0}$ is the concentration of organics in the bulk solution and $c_{s}$ is the concentration of organics in the bubble subsurface. Assuming that the bubble interface is in equilibrium with the subsurface following a Langmuir isotherm, the solution of this differential equation yields (Morgan et al., 1992):

$t=\frac{\delta}{D c_{0}} \frac{\Gamma_{\mathrm{eq}}}{\Gamma_{\infty}}\left[\Gamma-\Gamma_{\mathrm{eq}} \ln \left(1-\frac{\Gamma}{\Gamma_{\mathrm{eq}}}\right)\right]$ where $t$ is the time, $\Gamma_{\text {eq }}$ is the equilibrium surface excess and $\Gamma_{\infty}$ is the saturation surface excess. This equation can be integrated if the equilibrium adsorption isotherm of the surfactants on study is known. For surfactant concentrations in the liquid bulk phase below the critical micelle concentration, the interfacial surface excess $\Gamma$ at a constant temperature can be described by the Gibbs isothermal adsorption equation (Gibbs, 1928):

$\Gamma=-\frac{1}{R T} \frac{d \sigma}{d \ln c_{0}}$

where $\sigma$ is the equilibrium surface tension at the air-water interface. Neglecting interactions of the surfactant molecules within the absorption layer, one can describe the adsorption of surface active materials at an interface using the Langmuir isothermal equation (Langmuir, 1917):

$\Gamma_{\text {eq }}=\Gamma_{\infty} \frac{c_{0}}{c_{0}+a_{L}}$

where $a_{L}$ is the Langmuir parameter (concentration at half surface coverage). This equation is a good approximation for the equilibrium relationship between the surface excess $\Gamma_{\text {eq }}$ at the interface and the surfactant concentration in the liquid phase. A relationship between the interfacial tension and the surfactant bulk concentration can be obtained by combining the Gibbs and Langmuir isotherms, which gives as a result the Langmuir-Szyskowski isotherm (Dukhin et al., 1995):

$\sigma=\sigma_{0}-R T \Gamma_{\infty} \ln \left(1+1 / a_{L} c_{0}\right)$

where $\sigma_{0}$ is the surface tension of pure water. Fitting the Langmuir-Szyskowski adsorption isotherm to the surface tension- $T$. rotula exudate concentration curve obtained by axisymmetrical shape analysis yields values of $\Gamma_{\infty}$ and $a_{L}$ of $3.6 \times 10^{-6} \mathrm{~mol} \mathrm{~m}^{-2}$ and $3.75 \mathrm{~mol} \mathrm{~m}^{-3}$, respectively (Fuentes et al., 2010). The value of $\Gamma_{\infty}$ used is consistent with the range of saturation surface excess values determined from the adsorption of marine surfactants on the air-water interface (Pogorzelski and Kogut, 2001b).

The evolution of the surface excess concentration with time can be derived by using Eq. (10), with the values of equilibrium surface excess $\Gamma_{\text {eq }}$ obtained from the Langmuir isotherm (Eq. 12). The approach to equilibrium for T. rotula exudate at the concentration of this study is illustrated in Fig. 12. For the determination of the exudate concentration corresponding to $512 \mu \mathrm{M}$ DOC organic content we used a biogenic molecule to carbon mass ratio of 1.87 , as determined from the phytoplackton biomass stoichiometry (Fraga, 2001). We find that the time required for equilibrium adsorption on a rising bubble is lower than $0.05 \mathrm{~ms}$, which is rapid on the timescale of our experiments $(>0.3 \mathrm{~s}$, Fig. 11). The time to reach equilibrium decreases with increasing bubble size as a result of the higher transport by convection induced by the higher velocity of large bubbles. In our experiments, the bubble surface excess is not expected to be transport limited as equilibrium surface coverage is rapidly established, 


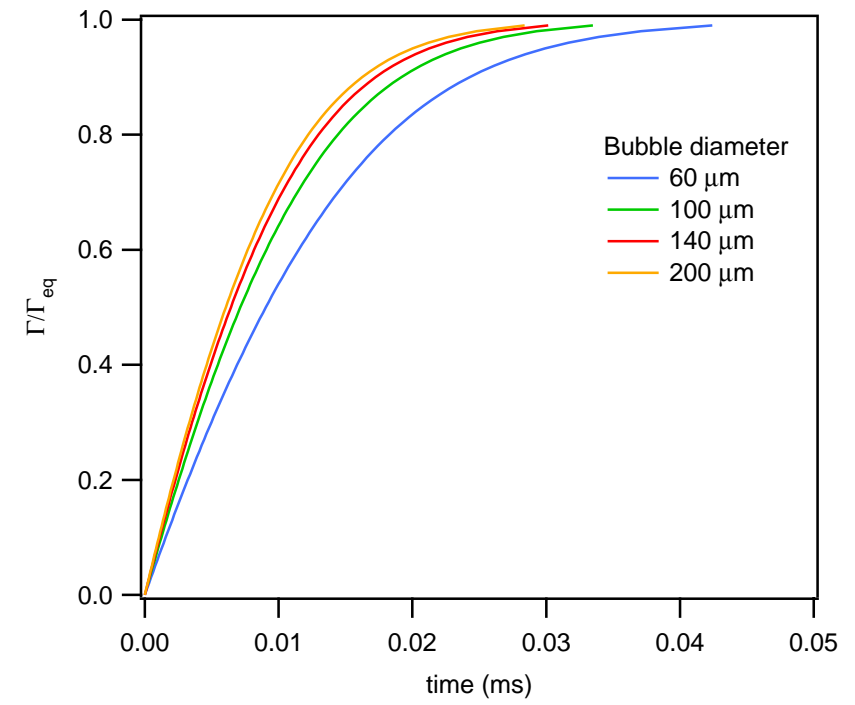

Fig. 12. Prediction of $\Gamma / \Gamma_{\text {eq }}$ ratio as a function of time for bubbles generated by a small-scale plunging water jet in a solution with $5.77 \mu \mathrm{M}$ T. rotula exudate concentration. The exudate concentration corresponds to $512 \mu \mathrm{M}$ DOC organic content (biogenic molecule to $\mathrm{C}$ mass ratio $=1.87$ (Fraga, 2001)).

thus the experimental system employed should be valid for this type of study. It should also be taken into account that the concentration of organic matter in the tank will evolve to a distribution characterized by the highest concentration near the water surface, as a result of the diffusion of surfactants to the air-water interface (Stefan and Szeri, 1999), thus, the shallow bubble plumes produced in our study spend their lifetime in the relevant region for organics adsorption.

According to these results the differences observed between the different bubble-bursting mechanisms would not be related to the different bubble paths. We suggest that the higher number of bubbles generated by the 8 water jets system with respect to the spargers (estimated to be about double amount with respect to the glass frit) might explain the differences observed in the hygroscopicity and $\mathrm{CCN}$ measurements between the bubble-bursting systems. A higher number of bubbles imply more transport of organic matter to the water subsurface (Stefan and Szeri, 1999), which would lead to higher local organic concentration near the bubble bursting region and, hence, to higher particle organic enrichment. Further work with the same system and different bubble production should be conducted in order to clarify this aspect.

\section{Summary and conclusions}

Different laboratory marine aerosol generation techniques were evaluated in order to assess if the mechanism for bubble/particle production affects the properties of the generated aerosol. Two porous bubblers and a plunging-water jet system were tested as bubble-bursting aerosol generators for comparison with a standard nebulizer. The systems for aerosol production were evaluated by analysing the bubble spectrum generated by the bubble-bursting methods and the size distribution, hygroscopicity and $\mathrm{CCN}$ activity of the aerosols generated by the different techniques.

The bubble spectrum obtained with the plunging-water jet system resembled the real oceanic spectrum with a dominant peak at $20-40 \mu \mathrm{m}$ and a typical oceanic power-law scaling profile with exponents ranging from 1.4 to 4.5. Comparison of the power-law exponents with real spectrum measurements near bubble formation indicated that the nascent plume generated by the plunging-water jet mimics an acoustic bubble plume which evolves to a quiescent state as it is dispersed in the water bulk.

The multimodal aerosol size distributions obtained with the different generators were decomposed into single lognormal modes in order to compare and identify the different mechanisms contributing to the formation of the aerosol. Three bubble-bursting related modes and one foam/splashing related mode were found in the bubble-bursting techniques distributions, whereas only two modes comprised the atomizer particle size distribution. Differences between the shape of the different particle size distributions is attributed to the different mechanisms employed.

Hygroscopic growth of particles generated from artificial seawater occurred at lower relative humidities than that of $\mathrm{NaCl}$, but similar growth to the pure salt was obtained above $75 \%$ RH. No observable differences were found between the behaviour of the aerosol generated from artificial seawater by the different techniques. Hygroscopic growth was suppressed with respect to the organics-free artificial seawater experiments when the aerosol was generated from filtered seawater enriched with biogenic surfactants, although the extent of this reduction was dependent on the aerosol generation technique applied.

Likewise, the CCN activity of particles generated from artificial seawater did not show observable differences with respect to that of pure $\mathrm{NaCl}$ when using the different techniques. However, the use of organics-enriched natural seawater as parent solution produced an increase in the critical supersaturation with respect to the case without organics. The extent of this effect was dependent on the aerosol generator employed. A large effect was observed for the atomization experiments, with a notable increment in the critical supersaturation with increasing particle size with respect to the case without organics. Reduced effects were observed for the bubbling-bursting methods, with a $17 \%$ increase for the plunging- water jet and $11 \%$ for the porous aerators.

Comparison between bubble-bursting scaled systems and the oceanic conditions indicated that bubble lifetimes in the laboratory systems are shorter than those in oceanic bubble swarms. In the case of plunging water jets this is due to the low void fractions and shallow plumes generated, while for glass frits the low residence times are the result of low void fractions and significant wake effects. It would require 
a considerable extension of the bubble path length in systems with spargers to replicate the oceanic bubble lifetimes. Available evidence suggests that the best system to reproduce the oceanic bubble lifetimes is the generation of large-scale highspeed plunging water jets, able to produce deep plumes and large void fractions.

Theoretical analysis of the kinetics of adsorption of marine organics on rising bubbles showed that the time required for adsorption equilibrium to be reached is lower than $0.05 \mathrm{~ms}$, which is rapid on the timescale of bubble residence in scaled systems. The bubble surface excess is not expected to be transport limited as equilibrium surface coverage is rapidly established. Hence, laboratory scaled systems are valid for conducting studies on marine organics effects on the sea spray aerosol.

The results of this work have demonstrated that different mechanisms for aerosol production in the laboratory lead to diverging experimental results in the aerosol behaviour. Consensus in the use of a proper marine aerosol generator for these types of studies is therefore needed to make laboratory experiments comparable. A plunging water jet system is able to produce bubble populations that resemble the real powerlaw bubble spectrum profile, whilst it involves the reproduction of the physical process of bubble formation by water impingement. Thus, a system demonstrating these characteristics is expected to generate particles whose behaviour is more representative of primary marine aerosols compared to other laboratory generators.

Acknowledgements. This work was supported by the UK Natural Environment Research Council [grant numbers NE/D005175/1 and NE/G000247/1]. The authors would like to thank Leo H. Cohen from the Netherlands Organisation for Applied Scientific Research (TNO) for his cooperation and assistance in the use of the BMS instrument.

Edited by: A. Wiedensohler

\section{References}

Aluwihare, L. I. and Repeta, D. J.: A comparison of the chemical characteristics of oceanic DOM and extracellular DOM produced by marine algae, Mar. Ecol. Prog. Ser., 186, 105-117, 1999.

Baldy, S.: Bubbles in the close vicinity of breaking waves: Statistical characteristics of the generation and dispersion mechanism, J. Geophys. Res., 93(C7), 8239-8248, 1988.

Batchelor, G. K.: An Introduction to Fluid Dynamics, Cambridge University Press, Cambridge, 1967.

Blanchard, D. C.: Sea-to-air transport of surface active material, Science, 146, 396-397, 1964.

Boehme, J., Frisches, M. E., Jiang, S. C., Kellog, C. A., Pichard, S., Rose, J. B., Steinway, C., and Paul, J. H.: Viruses, bacterioplankton, and phytoplankton in the southeastern Gulf of Mexico: distribution and contribution to oceanic DNA pools, Mar. Ecol. Prog. Ser., 97, 1-10, 1993.
Bowyer, P. A.: Video measurements of near-surface bubble spectra, J. Geophys. Res., 106(C7), 14179-14190, 2001.

Braban, C. F, Adams, J. W., Rodriguez, D., Cox, R. E., Crowley, J. N., and Schuster, G.: Heterogeneous reactions of HOI, ICl and $\mathrm{IBr}$ on sea salt and sea salt proxies, Phys. Chem. Chem. Phys., 9, 3136-3148, 2007.

Cavalli, F., Facchini, M. C., Decesari, S., Mircea, M., Emblico, L., Fuzzi, S., Ceburnis, D., Yoon, Y. J., ODowd, C D., Putaud, J. P., and DellAcqua, A. L.: Advances in characterization of size-resolved organic matter in marine aerosol over the North Atlantic, J. Geophys. Res., 109, D24215, doi:10.1029/2004JD005137, 2004.

Chanson, H., Aoki, D., and Maruyama, M.: Unsteady air bubble entrainment and detrainment at a plunging breaker: dominant time scales and similarity of water level variations, Coastal Eng., 46(2), 139-157, 2002.

Chanson, H., Aoki, D., and Maruyama, M.: Physical modelling and similitude of air bubble entrainment at vertical circular plunging jets, Chem. Eng. Sci., 59(4), 747-758, 2004.

Cipriano, R. J. and Blanchard, D.: Bubble and Aerosol Spectra Produced by a Laboratory "Breaking Wave", J. Geophys. Res., 86(C9), 8085-8092, 1981.

Cloke, J., McKay, W. A., and Liss, P. S.: Laboratory investigations into the effect of marine organic material on the sea-salt aerosol generated by bubble bursting, Mar. Chem., 34, 77-95, 1991.

Cziczo, D. J., Nowak, J. B.,. Hu, J. H., and Abbatt, J. P. D.: Infrared spectroscopy of model tropospheric aerosols as a function of relative humidity: Observation of deliquescence and crystallization, J. Geophys. Res., 102, 18843-18850, 1997.

Cubison, M. J., Coe, H., and Gysel, M.: A modified hygroscopic tandem DMA and a data retrieval method based on optimal estimation, J. Aerosol. Sci., 36, 846-865, 2005.

de Leeuw, G. and Cohen, L. H.: Bubble size distributions on the North atlantic and North Sea. Geophysical monograph, Am. Geo. Union, 127, 271-277, 2002.

de Leeuw, G. and Leifer, I.: "Bubbles outside the bubble plume during the LUMINY wind-wave experiment”, in: Gas Transfer and Water Surfaces, edited by: Donelan, M. A., Drennan, W. M., Salzman, E. S., and Wanninkhof, R., Geophysical Monograph 127, American Geophysical Union, Washington DC, 295-301, 2002.

Deane, G. B. and Stokes, M. D.: Scale dependence of bubble creation mechanisms in breaking waves, Nature, 418, 839-844, 2002.

Dinar, E., Mentel, T. F., and Rudich, Y.: The density of humic acids and humic like substances (HULIS) from fresh and aged wood burning and pollution aerosol particles, Atmos. Chem. Phys., 6, 5213-5224, 2006, http://www.atmos-chemphys.net/6/5213/2006/.

Duce, R. A. and Hoffman, E. J.: Chemical fractionation at the air/sea interface, Annu. Rev. Earth Pl. Sc., 4, 187-228 , 1976.

Dukhin, S. S., Kretschmar, G., and Miller, R.: Dynamics of adsorption at liquid interfaces, Elsevier Verlag, Amsterdam, 1995.

Facchini, M.C., Rinaldi, M., Decesari, S., Carbone, C., Finessi, E., Mircea, M., Fuzzi, S., Ceburnis, D., Flanagan, R., Nilsson, E.D, de Leeuw, G., Martino, M.,Woeltjen, J., and O'Dowd, C. D.: Primary submicron marine aerosol dominated by insoluble organic colloids and aggregates, Geophys. Res. Lett., 35, L17814, doi:10.1029/2008GL034210, 2008. 
Fitzgerald, J. W.: Marine aerosols: a review, Atmos. Environ., 25A, 533-546, 1991.

Fraga, F.: Phytoplanktonic biomass synthesis: application to deviations from Redfield stoichiometry, Sci. Mar., 65, supplement 2, 153-169, 2001.

Fuentes, E., Coe, H., Green, D., and McFiggans, G.: On the impacts of phytoplankton-derived organic matter on the properties of primary marine aerosol, in preparation, 2010.

Gibbs, J. W.: Collected Works Longmans, Green and Co., New York, 1928.

Graham, A., Woolf, D. K., and Hall, A. J.: Aeration due to breaking waves. Part I: Bubble populations, J. Phys. Oceanogr., 34, 9891007, 2004.

Guillard, R. R. L.: Culture of phytoplankton for feeding marine invertebrates, in: Culture of Marine Invertebrate Animals, edited by: Smith, W. L. and Chanley, M. H., Plenum Press, New York, 26-60, 1975.

Gysel, M., McFiggans, G. B., and Coe, H.: Inversion of tandem differential mobility analyser (TDMA) measurements, J. Aerosol Sci., 40, 134-151, 2009.

Hoffman, E. J. and Duce, R. A.: Organic carbon in marine atmospheric particulate matter: concentration and particle size distribution, Geophys. Res. Lett., 4, 449-452, 1977.

Hultin, K. A. H., Nilsson, E. D., Krejci, R., Mårtensson, E. M., Hagstrom, A., and de Leeuw, G.: In situ laboratory sea spray production during the MAP 2006 cruise on the North East Atlantic, J. Geophys. Res., doi:10.1029/2009JD012522, in press, 2010.

Hwang, P. A., Hsu, Y.-H. L., and Wu, J.: Air Bubbles Produced by Breaking Wind Waves: A Laboratory Study, J. Phys. Oceanogr., 20(1), 19-28, 1990.

Hwang, P. A. and Teague, W. J.: Low-Frequecy Resonant Scattering of Bubble Clouds, J. Atmos. Oceanic Technol., 17(6), 847-853, 2000 .

Iskandar, F., Gradon, L., and Okuyama, K.: Control of the morphology of nanostructured particles prepared by the spray drying of a nonparticle sol, J. Col. Interf. Sci., 265, 396-303, 2003.

Ittekot, V.: Variations of dissolved organic matter during a plankton bloom: qualitative aspects, based on sugar and amino acid analyses., Mar. Chem., 11, 143-158, 1982.

Johnson, B. D.: Bubble populations: background and breaking waves, in: A Parameter Describing Overall Conditions of Wave Breaking, Whitecapping, Sea-spray Production and Wind Stress, Oceanic Whitecaps and Their Role in Air-Sea Exchange Processes, edited by: Monahan, E. C., McGrawHill Editors, Reidel, Dordrecht, The Netherlands, 69-75, 1986.

Keene, W. C., Maring, H. , Maben, J. R., Kieber, D. J., Pszenny, A. A. P., Dahl, E. E., Izaguirre, M. A., Davis, A. J., Long, M. S., Zhou, X., Smoydzin, L., and Sander, R.: Chemical and physical characteristics of nascent aerosols produced by bursting bubbles at a model air-sea interface, J. Geophys. Res., 112, D21202, doi:10.1029/2007JD008464, 2007.

Kester, D. R., Duedall, I. W., Conners, D. N., and Pytkowicz, R. M.: Preparation of artificial seawater, Limnol. Oceanogr., 12, 176179,1967

Krzan, M. and Malysa, K.: Influence of solution $\mathrm{pH}$ and electrolyte presence on bubble velocity in anionic surfactant solutions, Physicochem. Probl. Mi., 43, 43-58, 2009.
Lamarre, E. and Melville, W. K.: Air entrainment and dissipation in breaking waves, Nature, 351, 469-472, 1991.

Lamarre, E. and Melville, W. K.: Sound-speed measurements near the ocean surface, J. Acoust. Soc. Amer., 96, 3605-3616, 1994.

Langmann, B., Scannel, C., and O'Dowd, C.: New Directions: Organic matter contribution to marine aerosols and cloud condensation nuclei, Atmos. Environ., 42(33), 7821-7822, 2008.

Langmuir, I.: The constitution and fundamental properties of solids and liquids. II. Liquids, Am. Chem. Soc., 39, 1848-1906, 1917.

Leifer, I., de Leeuw, G., and Cohen, L. H.: Secondary bubble production from breaking waves: The bubble burst mechanism, Geophys. Res. Lett., 27, 4077-4080, 2000.

Leifer, I., de Leeuw, G., and Cohen, L. H.: Optical Measurement of Bubbles: System Design and Application, J. Atmos. Ocean. Technol., 20, 1317-1332, 2003.

Leifer, I. and de Leeuw, G.:, Bubbles generated from windsteepened breaking waves: 1 . Bubble plume bubbles, J. Geophys. Res., 111, C06020, doi:10.1029/2004JC002673, 2006.

Leifer, I., Caulliez, G., and De Leew, G.: Characteristics of bubble plumes, bubble-plume bubbles, and waves from wind-steepened wave-breaking, J. Mar. Syst., 66, 61-70, 2007.

Levich, V. G.: Physicochemical Hydrodynamics, 2nd ed.; PrenticeHall: Englewood Cliffs, NJ, Chapter 8, Section 72, 1962.

Lewis, E. R. and Schwartz, S. E.: Sea Salt Aerosol Production: Mechanisms, Methods, Measurements and Models, Geophysical Monograph Series, American Geophysical Union, Washington, DC, 152, 252 pp., 2004.

Li, Z., Williams, A. L., and Rood, M. J.: Influence of soluble surfactant properties on the activation of aerosol particles containing inorganic solute, J. Atmos. Sci., 55, 1859-1866, 1998.

Lomas, M. W., Glibert, P. M., Clougherty, D. A., Huber, D., R., Jones, J., Alexander, J., and Haramoto, E. Elevated organic nutrient ratios associated with brown tide algal blooms of Aureococcus anophagefferens (Pelagophyceae), J. Plankton Res., 23(12), 1339-1344, 2001.

Mårtensson, E. M. , Nilsson, E. D., Cohen, L. H., and de Leeuw, G.: Laboratory simulations and parameterization of the primary marine aerosol production, J. Geophys. Res., 108(D9), 4297, doi:10.1029/2002JD002263, 2003.

McFiggans, G., Artaxo, P., Baltensperger, U., Coe, H., Facchini, M. C., Feingold, G., Fuzzi, S., Gysel, M., Laaksonen, A., Lohmann, U., Mentel, T. F., Murphy, D. M., O’Dowd, C. D., Snider, J. R., and Weingartner, E.: The effect of physical and chemical aerosol properties on warm cloud droplet activation, Atmos. Chem. Phys., 6, 2593-2649, 2006, http://www.atmos-chem-phys.net/6/2593/2006/.

McNeill, V. F., Patterson, J., Wolfe, G. M., and Thornton, J. A.: The effect of varying levels of surfactant on the reactive uptake of $\mathrm{N}_{2} \mathrm{O}_{5}$ to aqueous aerosol, Atmos. Chem. Phys., 6, 1635-1644, 2006, http://www.atmos-chem-phys.net/6/1635/2006/.

Medwin, H. and Breitz, N. D: Ambient and Transient Bubble Spectral Densities in Quiescent Seas and Under Spilling Breakers, J. Geophys. Res., 94(C9), 12751-12759, 1989.

Meskhidze, N. and Nenes, A.: Phytoplankton and cloudiness in the Southern Ocean, Science, 314(5804), 1419-1423, 2006

Middlebrook, A. M., Murphy, D. M., and Thomson, D. S.: Observation of organic material in individual particles at Cape Grim during the First Aerosol Characterization Experiment (ACE 1), J. Geophys. Res., 103(D13), 16475-16483, 1998. 
Moore, R. H., Ingall, E. D., Sorooshian, A., and Nenes, A.: Molar mass, surface tension, and droplet growth kinetics of marine organics from measurements of CCN activity, Geophys. Res. Lett., 35, L07801, doi:10.1029/2008GL033350, 2008.

Morgan, J. D., Napper, D. H., Warr, G. G., and Nicol, S. K.: Kinetics of recovery of hexadecyltrimethylammonium bromide by flotation, Langmuir, 8, 2124-2129, 1992.

Niedermeier, D., Wex, H., Voigtländer, J., Stratmann, F., Brüggemann, E., Kiselev, A., Henk, H., and Heintzenberg, J.: LACIS-measurements and parameterization of sea-salt particle hygroscopic growth and activation, Atmos. Chem. Phys., 8, 579590, 2008, http://www.atmos-chem-phys.net/8/579/2008/.

Novakov, T., Corrigan,C. E., Penner, J. E., Chuang, C. C., Rosario, O., and Bracero, O. L.: Organic aerosols in the Caribbean trade winds: A natural source?, J. Geophys. Res., 102(D17), 2130721313, doi:10.1029/97JD01487, 1997.

O’Dowd, C. D., Smith, M. H., Consterdine, I. E., and Lowe, J. A.: Marine aerosol, sea-salt, and the marine sulphur cycle: a short review, Atmos. Environ., 31, 73-80, 1997.

O’Dowd, C. D., Facchini, M. C., Cavalli, F., Ceburnis, D., Mircea, M., Decesari, S., Fuzzi, S., Yoon, Y. J., and Putaud, J.-P.: Biogenically driven organic contribution to marine aerosol, Nature, 431(7009), 676680, 2004.

O'Dowd, C. D. and de Leeuw, G.: Marine aerosol production: a review of the current knowledge, Philos. Trans. R. Soc., 365, 2007-2043, 2007.

Pogorzelski, S. J. and Kogut, A. D.: Static and dynamic properties of surfactant films on natural waters, Oceanologia, 43(2), 223224, 2001a.

Pogorzelski, S. J. and Kogut, A. D.: Kinetics of marine surfactant adsorption at an air/water interface. Baltic Sea studies, Oceanologia, 43(4), 389-404, 2001b.

Putaud, J. P., Van Dingenen, R., Mangoni, M., Virkkula, A., Raes, F., Maring, H., Prospero, J. M., Swietlicki, E., Berg, O. H., Hillamo, R., and Makela, T.: Chemical mass closure and assessment of the origin of the submicron aerosol in the marine boundary layer and the free troposphere at Tenerife during ACE2, Tellus B, 52, 141-168, 2000.

Ramaswamy, V., Boucher, O., Haigh, J., Hauglustaine, D., Haywood, J., Myhre, G., Nakajima, T., Shi, G. Y., and Solomon, S.: Climate Change 2001: The Scientific Basis. Contribution of working group I to the Third Assessment Report of the Intergovernmental Panel on Climate Change, 2001.

Rapp, R. J. and Melville, W. K.: Laboratory measurements of deepwater breaking waves, Philos. T. R. Soc. Lond., 331, 735-800, 1990.

Ribeiro C. P. and Mewes, D.: The influence of electrolytes on gas hold-up and regime transition in bubble columns, Chem. Eng. Sci., 62(17), 4501-4509, 2007.

Richardson, J. F. and Zaki, W. N.: Sedimentation and fluidizationpart I, T. I. Chem. Eng.-Lond., 32, 35-53, 1954.

Rissman, T. A., Varutbangkul, V., Surratt, J. D., Topping, D. O., McFiggans, G., Flagan, R. C., and Seinfeld, J. H.: Cloud condensation nucleus $(\mathrm{CCN})$ behavior of organic aerosol particles generated by atomization of water and methanol solutions, Atmos. Chem. Phys., 7, 2949-2971, 2007,

http://www.atmos-chem-phys.net/7/2949/2007/.
Abo Riziq, A., Erlick, C., Dinar, E., and Rudich, Y.: Optical properties of absorbing and non-absorbing aerosols retrieved by cavity ring down (CRD) spectroscopy, Atmos. Chem. Phys., 7, 15231536, 2007, http://www.atmos-chem-phys.net/7/1523/2007/.

Roberts, G. C. and Nenes, A.: A continuous-flow streamwise thermal-gradient $\mathrm{CCN}$ chamber for atmospheric measurements, Aerosol Sci. Tech. 39, 206-221, 2005.

Ruzicka, M. C., Draho J., Menab, P. C., and Teixeirac, J. A., Chem. Eng. J., 96(1-3), 15-22, 2003.

Sankaranarayanan, K., Shan, X. , Kevrekidis, I. G., and Sundaresan, S.: Analysis of drag and virtual mass forces in bubbly suspensions using an implicit formulation of the lattice Boltzmann method, J. Fluid Mech., 452, 61-96, 2002.

Saul, T. D., Tolocka, M. P., and Johnston, M. V.: Reactive uptake of nitric acid onto sodium chloride aerosols across a wide range of relative humidities, J. Phys. Chem. A, 110, 7614-7620, 2006.

Savoie, D. L., Arimoto, R., Keene, W. C., Prospero, J. M., Duce, R. A., and Galloway, J. N.: Marine biogenic and anthropogenic contributions to non-sea-salt sulfate in the marine boundary layer over the North Atlantic Ocean, J. Geophys. Res., 107(D18), 4356, doi:10.1029/2001JD000970, 2002.

Sellegri, K, O’Dowd, C. D., Yoon, Y. J, Jennings, S. G., and de Leeuw, G.: Surfactants and submicron sea spray generation, J. Geophys. Res., 111, D22215, doi:10.1029/2005JD006658, 2006.

Simonnet, M., Gentric, C., Olmos E., and Midoux, N. Experimental determination of the drag coefficient in a swarm of bubbles, Chem. Eng. Sci., 62, 858-866, 2007.

Sorjamaa, R., Svenningsson, B., Raatikainen, T., Henning, S., Bilde, M., and Laaksonen, A.: The role of surfactants in Köhler theory reconsidered, Atmos. Chem. Phys., 4, 2107-2117, 2004, http://www.atmos-chem-phys.net/4/2107/2004/.

Spiel, D. E.: A hypothesis concerning the peak in film drop formation as a function of bubble size, J. Geophys. Res., 102(C1), 1153-1161, doi:10.1029/96JC03069, 1997.

Stefan, R. L. and Szeri, A. J.: Surfactant scavenging and surface deposition by rising bubbles, J. Coll. Int. Sci., 212, 1-13, 1999.

Stephanou, E. G.: Analysis of anthropogenic and biogenic lipids in the aerosol of a coastal area in East Mediterranean Sea, Fresen. J. Anal. Chem., 339, 780-784, 1991.

Stewart, D. J., Griffiths, P. T., and Cox, R. A.: Reactive uptake coefficients for heterogeneous reaction of $\mathrm{N}_{2} \mathrm{O}_{5}$ with submicron aerosols of $\mathrm{NaCl}$ and natural sea salt, Atmos. Chem. Phys., 4, 1381-1388, 2004,

http://www.atmos-chem-phys.net/4/1381/2004/.

Svenningsson, B., Rissler, J., Swietlicki, E., Mircea, M., Bilde, M., Facchini, M. C., Decesari, S., Fuzzi, S., Zhou, J., Mønster, J., and Rosenørn, T.: Hygroscopic growth and critical supersaturations for mixed aerosol particles of inorganic and organic compounds of atmospheric relevance, Atmos. Chem. Phys., 6, 1937-1952, 2006 , http://www.atmos-chem-phys.net/6/1937/2006/.

Taketani, F., Kanaya, Y., and Akimoto, H., Heterogeneous loss of $\mathrm{HO}_{2}$ by $\mathrm{KCl}$, synthetic sea salt, and natural seawater aerosol particles, Atmos. Environ., 43(9), 1660-1665, 2009.

Tang, I. N., Tridico, A. C., and Fung, K. H.: Thermodynamical and optical properties of sea salt aerosols, J. Geophys. Res., 102, 23269-23275, 1997. 
Terrill, E. J., Melville, W. K., and Stramski, D.: Bubble entrainment by breaking waves and their influence on optical scattering in the upper ocean, J. Geophys. Res., 106(C8), 16815-16823, 823, 2001.

Tseng, R., Viechnicki, J. T., Skop, R. A., and Brown, J. W.: Seato Air transfer of surface active organic compounds by bubble bursting bubbles, J. Geophys. Res., 97, 5201-5206, 1992.

Tyree, C. A., Hellion, V. M., Alexandrova, O. A., and Allen, J. O.: Foam droplets generated from natural and artificial seawaters, J. Geophys. Res., 112, D12204, doi:10.1029/2006JD007729, 2007.

Vagle, S. and Farmer, D. M.: The measurement of bubble-size distributions by acoustical backscatter, J. Atmos. Ocean. Tech., 9, 630-644, 1992.

Williams, P. I.: Construction and validation of a DMPS for aerosol characterisation, University of Manchester, PhD Thesis, 1999.

Williams, P. I., McFiggans, G., and Gallagher, M. W.: Latitudinal aerosol size distribution variation in the Eastern Atlantic Ocean measured aboard the FS-Polarstern, Atmos. Chem. Phys., 7, 2563-2573, 2007,

http://www.atmos-chem-phys.net/7/2563/2007/.
Winkler, P. and Junge, C.: The growth of atmospheric aerosol particles as a function of the relative humidity, I, Methods and measurements at different locations, J. Res. Atmos., 18, 617-638, 1972.

Wise, M. E., Freney, E. J., Tyree, C. A., Allen, J. O., Martin, S. T., Russel, L. M. and Buseck, P. R.: Hygroscopic behaviour and liquid-layer composition of aerosol particles generated from natural and artificial seawater, J. Geophys. Res., 114, D03201, doi:10.1029/2008JA013848, 2009.

Wu, J.: Jet Drops Produced by Bubbles Bursting at the Surface of Seawater, J. Phys. Oceanogr., 32, 3286-3290, 2002.

Young, M. E., Carroad, P. A., and Bell, R. L.: Estimation of diffusion coefficients of proteins, Biotechnol. Bioeng., 22(5), 947955, 2004.

Zhang, J. and Fan, L.-S.: On the rise velocity of an interactive bubble in liquids, Chem. Eng. J., 92, 169-176, 2003. 